\title{
Two novel poty-like viruses identified from the transcriptome data of purple witchweed (Striga hermonthica)
}

\author{
Dongjin Choi ${ }^{1}$, Chaerim Shin¹, Ken Shirasu' ${ }^{2,3}$, Yoonsoo Hahn ${ }^{1^{*}}$
}

${ }^{1}$ Department of Life Science, Chung-Ang University, Seoul 06974, South Korea; ${ }^{2}$ RIKEN Center for Sustainable Resource Science, Yokohama, Kanagawa 230-0045, Japan; ${ }^{3}$ Graduate School of Science, The University of Tokyo, Bunkyo, Tokyo 113-0033, Japan

\begin{abstract}
Summary. - Potyvirids (the family Potyviridae) are the largest family of plant RNA viruses. Two novel potyvirid viruses, Striga-associated poty-like virus 1 (SaPlV1) and Striga-associated poty-like virus 2 (SaPlV2), were identified from the transcriptome data of purple witchweed (Striga hermonthica). SaPlV1 was most closely related to bellflower veinal mottle virus (BVMoV), the only member of the genus Bevemovirus, and then to macluraviruses (the genus Macluravirus). The SaPlV1 genome encodes a 2462 -amino acid (aa) polyprotein that may be cleaved into nine mature peptides. The cleavage sites of SaPlV1, BVMoV, and macluravirus polyproteins shared strong sequence similarities. SaPIV2 was most closely related to celery latent virus, the sole species of the genus Celavirus, which is the most divergent potyvirid genus. The SaP1V2 polyprotein contained 3329 aa and it may be cleaved into at least seven or eight mature peptides. Phylogenetic analysis suggested that SaPlV1 and SaPlV2 may be novel species of the genera Bevemovirus and Celavirus, respectively. The genome sequences of SaPlV1 and SaPlV2 are useful resources for studying the genome evolution of potyvirids.
\end{abstract}

Keywords: Striga-associated poty-like virus 1; Striga-associated poty-like virus 2; Potyviridae; Bevemovirus; Celavirus; purple witchweed; Striga hermonthica

\section{Introduction}

Potyviridae is the largest family of plant-infecting RNA viruses containing 235 species approved by the International Committee on Taxonomy of Viruses (ICTV) (https:// talk.ictvonline.org; ICTV Master Species List \#36, March 2021) (Gibbs et al., 2020; Palani et al., 2021). Potyvirids (members of the family Potyviridae) are classified into 12 genera:Arepavirus, Bevemovirus, Brambyvirus, Bymovirus, Celavirus, Ipomovirus, Macluravirus, Poacevirus, Potyvirus, Roymovirus, Rymovirus, and Tritimovirus (Palani et

"Corresponding author. E-mail: hahny@cau.ac.kr; phone: +822-820-5812.

Abbreviations: $\mathrm{BVMoV}=$ Bellflower veinal mottle virus; $\mathrm{CeLV}=$ Celery latent virus; $\mathrm{ORF}=$ open reading frame; $\mathrm{PIPO}=$ pretty interesting Potyviridae ORF; RdRp = RNA-dependent RNA polymerase; SaPlV1 = Striga-associated poty-like virus 1; SaPlV2 $=$ Striga-associated poty-like virus 2 al., 2021). Members of the genus Bymovirus have a bipartite genome, whereas those from the remaining 11 genera have a monopartite positive-sense single-stranded RNA genome (Revers and Garcia, 2015).

The genomic RNA of potyvirids encodes an open reading frame (ORF) for a large polyprotein, which undergoes proteolytic cleavage by virus-encoded proteases (Adams et al., 2005; Goh and Hahn, 2021; Palani et al., 2021). The polyprotein of potyviruses (the genus Potyvirus) is processed into ten mature peptides (from $\mathrm{N}$-terminus to $\mathrm{C}$-terminus): protein 1 protease (P1), helper component-protease (HCPro), protein 3 (P3), 6-kilodalton ( $\mathrm{kDa}$ ) peptide 1 (6K1), cylindrical inclusion protein (CI), 6-kDa peptide 2 (6K2), viral protein genome-linked (VPg), nuclear inclusion a protease (NIa-Pro), nuclear inclusion b protein (NIb), and coat protein (CP) (Adams et al., 2005; Goh and Hahn, 2021). P1 and HC-Pro proteases cleave themselves from the polyprotein, and NIa-Pro cleaves the remaining seven junctions. The NIb protein is an RNA-dependent RNA polymerase (RdRp) 
that is responsible for viral genome replication (Shen et al., 2020). Potyvirids from other genera have the same or similar genomic organization.

Eight mature peptides, P3, 6K1, CI, 6K2, VPg, NIa-Pro, $\mathrm{NIb}$, and $\mathrm{CP}$, are commonly produced from potyvirid polyproteins (Revers and Garcia, 2015). However, the P1 and HC-Pro segments among potyvirids are variable, probably resulting from diversifying evolution involving recombination and gene duplication (Valli et al., 2007). For example, macluraviruses (the genus Macluravirus) lack the $\mathrm{P} 1$ coding region and HC-Pro is absent in cassava brown streak virus (Mbanzibwa et al., 2009; Revers and Garcia, 2015; Elangovan et al., 2019).

An additional short ORF termed "pretty interesting Potyviridae ORF" (PIPO) is universally present within the $\mathrm{P} 3$ coding region of potyvirid genomes (Chung et al., 2008). A polymerase slippage inserts an additional A nucleotide within the highly conserved GAAAAAA $\left(\mathrm{GA}_{6}\right)$ motif. This insertion, termed " $+1 \mathrm{~A}$ insertion event," results in the formation of a "trans-frame" fusion protein with the $\mathrm{N}$ terminal half of P3 and PIPO; this protein is named the P3N-PIPO protein (Olspert et al., 2015; Rodamilans et al., 2015; White, 2015).

The majority of ICTV-approved Potyviridae species (190 out of 235) belong to the genus Potyvirus. The other 11 genera each contain one to ten recognized species. The genus Bevemovirus has a single approved species, the Bellflower veinal mottle virus (BVMoV), which was isolated from a bellflower (Campanula takesimana) (Seo et al., 2017). The BVMoV polyprotein is predicted to be cleaved to produce nine mature proteins, HC-Pro, P3, 6K1, CI, 6K2, VPg, NIaPro, NIb, and CP; this is the same as that of macluravirus polyproteins. Phylogenetic analysis using BVMoV and selected potyvirid polyprotein sequences suggested that the genus Bevemovirus is the sister taxon of the genus Macluravirus (Seo et al., 2017).

Celavirus is another genus represented by only one species, the Celery latent virus (CeLV), which was first identified in celery (Apium graveolens var. dulce) and celeriac (A.g. var. rapaceum) without visible symptoms (Bos et al., 1978; Rose et al., 2019). The CeLV polyprotein has a low sequence similarity to other potyvirid polyproteins, suggesting that Celavirus is the most divergent genus of the family Potyviridae (Rose et al., 2019).

RNA-Seq data obtained from plant tissue samples often contain genomic RNA or mRNA fragments derived from latently infected RNA viruses (Bejerman et al., 2020; Park and Hahn, 2021). Comprehensive analyses of diverse plant transcriptome data have yielded many novel RNA virus genome sequences (Park et al., 2018; Goh et al., 2021; Park et al., 2021; Park and Hahn, 2021). In this study, we identified the genome sequences of two novel viruses belonging to the genera Bevemovirus and Celavirus (the family Potyviridae) from the transcriptome data of purple witchweed (Striga hermonthica) (Yoshida et al., 2019). Purple witchweed is a hemiparasitic plant that infests grain crops, such as sorghum, maize, and sugar cane, and causes major grain losses (Spallek et al., 2013).

\section{Materials and Methods}

The purple witchweed transcriptome data analyzed in this study are available in the Sequence Read Archive (SRA) of the National Center for Biotechnology Information (NCBI) (Yoshida et al., 2019). The SRA Acc. Nos. are DRR183243, DRR183244, DRR183245, DRR183246, DRR183247, DRR183248, DRR183249, and DRR183250. RNA-Seq reads were trimmed using the sickle program (version 1.33; https://github.com/najoshi/sickle) with the parameter “-q30-155." Filtered high-quality reads from all nine sequencing runs were pooled into a single dataset and assembled into contigs using the rnaviralSPAdes pipeline of the SPAdes assembler (version 3.15.1; http://cab.spbu.ru/software/ spades) (Bushmanova et al., 2019).

Known viral RdRp domain sequences were downloaded from the Pfam database (release 33.1; https://pfam.xfam.org). Pfam Acc. Nos. for the viral RdRp families are PF00602, PF00603, PF00604, PF00680, PF00946, PF00972, PF00978, PF00998, PF02123, PF03035, PF03431, PF04196, PF04197, PF05788, PF05919, PF06317, PF07925, PF08467, PF08716, PF08717, PF12426, and PF17501. The DIAMOND program (version 2.0.4; http://www. diamondsearch.org/index.php) was used to compare the purple witchweed contigs and known viral RdRp sequences.

Sequencing depth was examined by mapping high-quality RNA-Seq reads to the contig sequence using the bwa-mem2 program (version 2.0pre2; https://github.com/bwa-mem2/bwamem2). Conserved domains in the polyprotein sequences were predicted using the InterPro web server (version 84.0; https:// www.ebi.ac.uk/interpro). The SignalP web server (version 5.0; https://services.healthtech.dtu.dk/service.php?SignalP) was used to predict the signal peptide.

Pairwise identities of the protein sequences were calculated using the needle program of the EMBOSS package (version 6.6.0.0; http://emboss.open-bio.org). Multiple sequence alignments were performed using the MAFFT program (version 7.475; https://mafft.cbrc.jp/alignment/software) (Nakamura et al., 2018). Gap-rich segments in the aligned sequences were removed using the trimAl program (version 1.4.rev22; http:// trimal.cgenomics.org) with the "-gappyout" option (CapellaGutierrez et al., 2009). A maximum-likelihood phylogenetic tree was constructed using the IQ-TREE program (version 2.1.2; http://www.iqtree.org) (Minh et al., 2020). Bootstrap supports were calculated from 1,000 replicates using the UFBoot2 method implemented in the IQ-TREE program. Sequence logos were generated using the WebLogo 3 server (http://weblogo. threeplusone.com) (Crooks et al., 2004). 


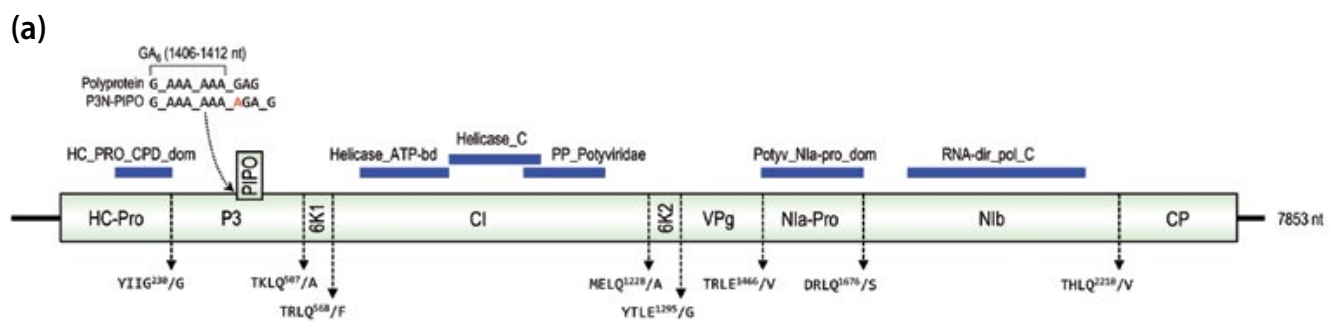

(b)

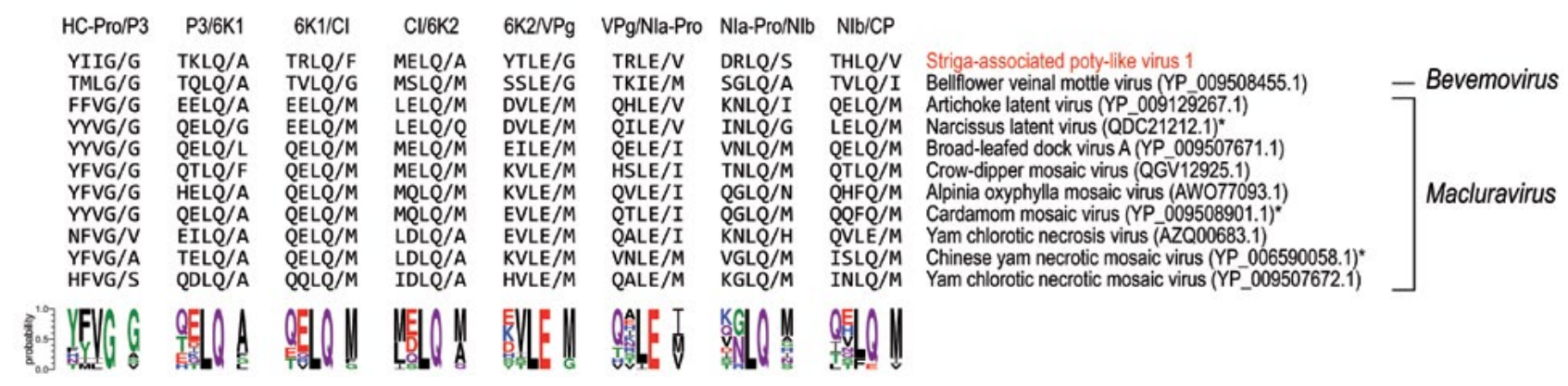

Fig. 1

Genome organization and cleavage sites of SaPlv1

(a) Schematic figure of the SaPIV1 genome is presented. ORFs for the large polyprotein and PIPO are depicted as boxes. Predicted InterPro domains are marked above the polyprotein ORF with the corresponding InterPro short name. The $\mathrm{GA}_{6}$ motif causing a polymerase slippage is shown above the genome (the +1A insertion is indicated in red and the underscores (' cleavage sites are presented below the polyprotein ORF.(b) Five aa resides at the eight cleavage sites of the SaPIV1, BVMoV, and nine macluravirus polyprotein sequences are presented. The slash ('/') indicates the cleaved bond. Three macluraviruses with annotated cleavage site information are indicated by asterisks. Sequence logos showing the frequencies of residues at each position are displayed at the bottom.

\section{Results and Discussion}

We re-analyzed the transcriptome data obtained for the investigation of gene expression dynamics during haustorium development in purple witchweed (Yoshida et al., 2019). Transcriptome contigs assembled from highquality RNA-Seq reads were compared with known viral RdRp sequences. Several contigs were found to contain a viral RdRp motif. Two different contigs showing significant sequence similarity to potyvirid RdRp motifs were chosen for further studies. To obtain a high-quality contig sequence, the sequencing depth of each contig was examined by mapping RNA-Seq reads to a contig, and bases supported by only one read were trimmed off at both ends. Two putative viral contigs that were 7853 and 10767 nucleotides ( $\mathrm{nt}$ ) in length were obtained.

BLASTX searches of the NCBI protein database using two contigs as query sequences confirmed that they encoded a large protein showing significant sequence similarity to known potyvirid polyproteins. Therefore, the 7853-nt and 10767-nt contigs were considered genome sequences of novel potyvirids and tentatively named Striga-associated poty-like virus 1 (SaPlV1) and Strigaassociated poty-like virus 2 (SaPlV2), respectively. The genome sequences were deposited in the NCBI database (Acc. Nos. MW699352 and MW699353, respectively).

Genome sequence of Striga-associated poty-like virus 1 (SaPlV1)

The SaPlV1 genome was 7853-nt long and predicted to encode a 2462-amino acid (aa) polyprotein (Fig. 1a and Table 1). The InterPro domain analysis indicated that the SaPlV1 polyprotein has conserved domains that are typically found in other potyvirid polyproteins, including the HC-Pro cysteine protease, helicase, NIa protease, and RdRp domains.

A sequence similarity search of all known viral proteins revealed that the SaPlV1 polyprotein was the most similar to the BVMoV polyprotein (NCBI Acc. No. YP_009508455.1), with 52.6\% identity in the 2496-aa overlap. BVMoV is a species within the genus Bevemovirus (Seo et al., 2017). The next similar sequences were polyproteins of various macluraviruses (the genus Macluravirus) such as the narcissus latent virus (QDC21212.1), cardamom mosaic virus(YP_009508901.1), and Chinese yam necrotic mosaic virus(YP_006590058.1), with 32\%-34\% identity in an approximately 2700-aa overlap (Kondo and Fujita, 2012; 
Table 1. ORFs and domains of SaPlV1 and SaPlV2 genome sequences

\begin{tabular}{|c|c|c|c|c|c|}
\hline Virus & ORF & $\begin{array}{c}\text { ORF } \\
\text { position (nt) }\end{array}$ & $\begin{array}{c}\text { Protein } \\
\text { length (aa) }\end{array}$ & $\begin{array}{c}\text { Domain } \\
\text { position (aa) }\end{array}$ & InterPro domain ${ }^{a}$ \\
\hline \multirow[t]{7}{*}{ SaPlV1 } & Polyprotein & $309-7679$ & 2462 & $113-230$ & $\begin{array}{l}\text { HC_PRO_CPD_dom (IPR031159): Helper-component proteinase } \\
\text { (HC-Pro) cysteine protease (CPD) domain-like methyltransferase } \\
\text { (MT) domain }\end{array}$ \\
\hline & & & & $625-810$ & $\begin{array}{l}\text { Helicase_ATP-bd (IPR014001): Helicase superfamily 1/2, } \\
\text { ATP-binding domain }\end{array}$ \\
\hline & & & & $810-1000$ & Helicase_C (IPR001650): Helicase, C-terminal \\
\hline & & & & $967-1136$ & PP_Potyviridae (IPR013648): Polyprotein, Potyviridae \\
\hline & & & & $1463-1674$ & $\begin{array}{l}\text { Potyv_NIa-pro_dom (IPR001730): Potyvirus NIa protease } \\
\text { (NIa-pro) domain }\end{array}$ \\
\hline & & & & $1769-2139$ & $\begin{array}{l}\text { RNA-dir_pol_C (IPR001205): RNA-directed RNA polymerase, } \\
\text { C-terminal domain }\end{array}$ \\
\hline & PIPO & $1412-1573$ & 53 & & \\
\hline \multirow[t]{4}{*}{ SaPlV2 } & Polyprotein & $278-10267$ & 3329 & $1180-1342$ & Helicase_C (IPR001650): Helicase, C-terminal \\
\hline & & & & 2067-2285 & $\begin{array}{l}\text { Potyv_NIa-pro_dom (IPR001730): Potyvirus NIa protease } \\
\text { (NIa-pro) domain }\end{array}$ \\
\hline & & & & $2381-2726$ & $\begin{array}{l}\text { RNA-dir_pol_C (IPR001205) RNA-directed RNA polymerase, } \\
\text { C-terminal domain }\end{array}$ \\
\hline & PIPO & $2047-2439$ & 130 & & \\
\hline
\end{tabular}

anterPro domain in the format of "short name (accession number): full name."

Elangovan et al., 2019; Wylie et al., 2019). Thus, SaPlV1 is the most closely related to BVMoV and possibly, a novel member of the genus Bevemovirus.

The polyprotein of potyvirids is post-translationally cleaved at conserved cleavage sites to produce mature peptides (Adams et al., 2005; Revers and Garcia, 2015; Goh and Hahn, 2021; Palani et al., 2021). BVMoV and macluravirus polyproteins are processed into nine mature peptides: HCPro, P3, 6K1, CI, 6K2, VPg, NIa-Pro, NIb, and CP (Revers and Garcia, 2015; Seo et al., 2017). The HC-Pro/P3 cleavage site is self-cleaved by HC-Pro, and the remaining seven sites are processed by NIa-Pro. To predict the putative cleavage sites and mature peptides of the SaPlV1 polyprotein, the polyprotein sequences of SaPlV1, BVMoV, and nine macluraviruses were multiply aligned (Supplementary Fig. S1 and Fig. 1b).

Based on the annotated cleavage sites of three macluraviruses (narcissus latent virus, cardamom mosaic virus, and Chinese yam necrotic mosaic virus), eight cleavage sites were predicted in the SaPlV1 polyprotein (see Fig. 1a for their positions). The predicted HC-Pro/P3 cleavage site was YIIG/G, which is highly similar to the potyvirus HCPro recognition sequence $Y X V G / G$, where ' $X$ ' indicates any aa and the slash ('/) indicates the cleaved bond (Adams et al., 2005; Goh and Hahn, 2021). Seven other predicted cleavage sites, which were processed by NIa-Pro, were TKLQ/A (P3/6K1), TRLQ/F (6K1/CI), MELQ/A (CI/6K2), YTLE/G (6K2/VPg), TRLE/V (VPg/NIa-Pro), DRLQ/S (NIaPro/NIb), and THLQ/V (NIb/CP). When the SaPlV1 NIa-Pro recognition sites were compared with those of BVMoV and macluraviruses, two consensus sequences were deduced: $\mathrm{XXLQ} / \mathrm{X}$ for five sites (P3/6K1, 6K1/CI, CI/6K2, NIa-Pro/ $\mathrm{NIb}$, and $\mathrm{NIb} / \mathrm{CP}$ ) and XXLE/X for two sites (6K2/VPg, VPg/NIa-Pro) (see Fig. 1b). The same pattern was also observed in bymoviruses (the genus Bymovirus), which are

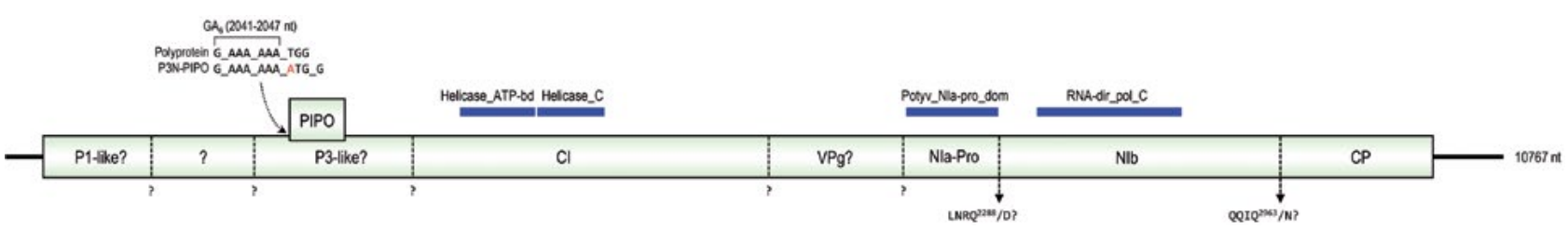

Fig. 2

Schematic figure of the putative genome organization of SaPIV2 Predicted genomic features of SaPlV2 are presented. See Fig. 1a for details. 


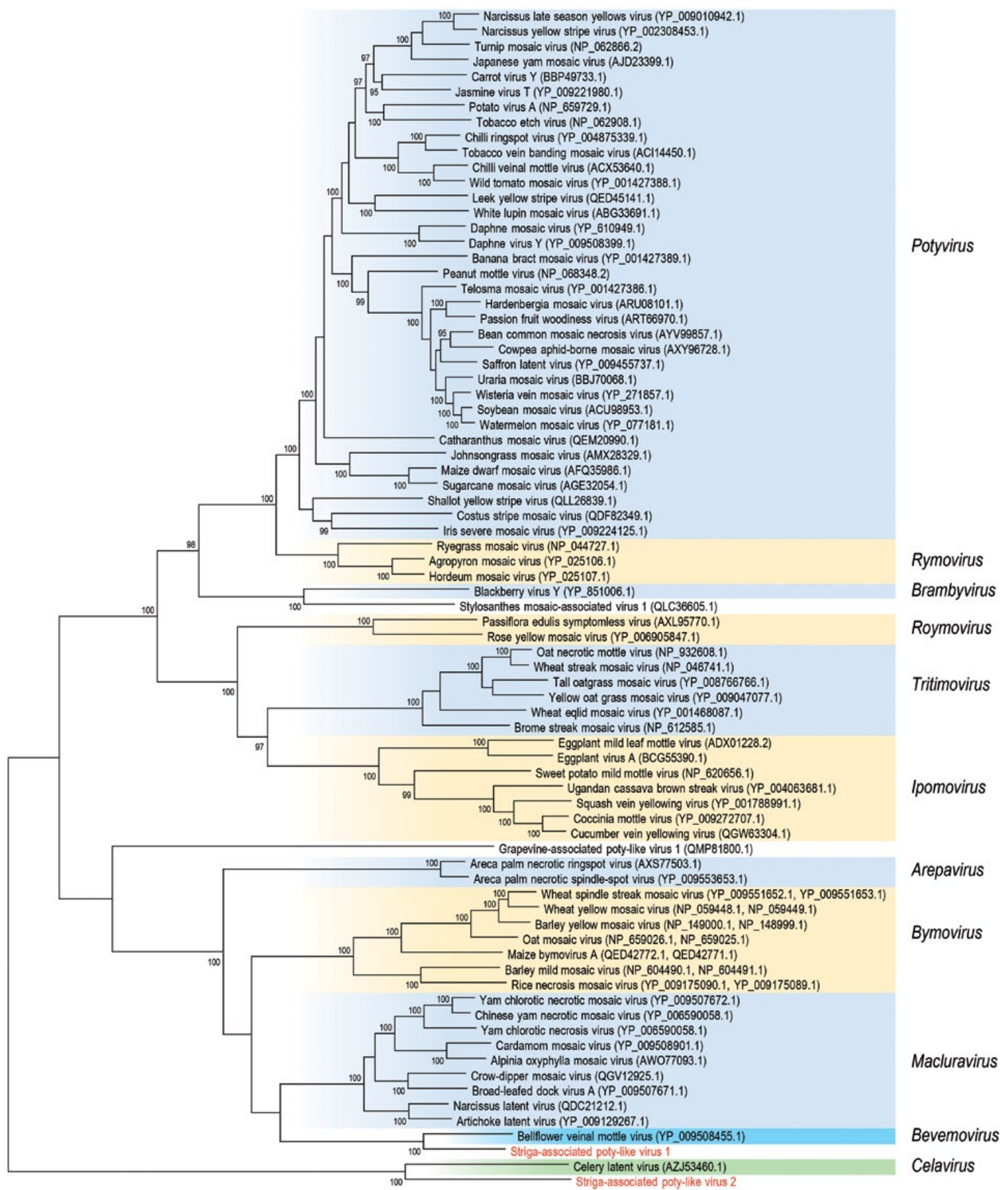

Phylogenetic relationships of SaPlV1 and SaPIV2 among Potyviridae viruses

A maximum-likelihood phylogenetic tree was constructed from the polyprotein sequences of SaPlV1, SaPlV2, and selected members of the family Potyviridae. The NCBI protein sequence accession numbers are shown in parentheses. Bootstrap supporting values of $95 \%$ or higher are shown at the nodes. 
more closely related to BVMoV and macluraviruses than to other potyvirids (Palani et al., 2021).

Potyviruses have an additional overlapping ORF termed PIPO within the P3 segment (Revers and Garcia, 2015; Gibbs et al., 2020). The trans-frame fusion protein $\mathrm{P} 3 \mathrm{~N}-\mathrm{PIPO}$ is produced by a $+1 \mathrm{~A}$ insertion in the A-tract of the $\mathrm{GA}_{6}$ motif by polymerase slippage (Olspert et al., 2015; White, 2015). There was only one $\mathrm{GA}_{6}$ motif in the SaPlV1 genome sequence within the P3 segment (nt 1406-1412) (Fig. 1a). To examine if the $+1 \mathrm{~A}$ insertion product was present in the purple witchweed transcriptome data, RNASeq reads were mapped to the SaPlV1 genome sequence. There were 18 reads spanning the $\mathrm{GA}_{6}$ motif. Among them, $17(94.44 \%)$ were the wild-type and $1(5.56 \%)$ was the $+1 \mathrm{~A}$ insertion product, suggesting that this position may be a polymerase slippage site.

The SaPlV1 small polyprotein sequence containing the 54-aa PIPO segment was deduced by inserting an A nucleotide within the A-tract of the $\mathrm{GA}_{6}$ motif. When the predicted SaPlV1 and BVMoV small polyprotein sequences were compared, the P3N and PIPO boundaries of both viruses exactly matched (Supplementary Fig. S2). The PIPO segments of the two viruses exhibited high sequence similarity, further indicating that the predicted $\mathrm{GA}_{6}$ motif was a genuine polymerase slippage site for the production of the trans-frame fusion protein P3N-PIPO.

Genome sequence of Striga-associated poty-like virus 2 (SaPlV2)

The SaPlV2 genome was 10767-nt long and predicted to encode a 3329-aa polyprotein (Fig. 2 and Table 1). The SaPlV2 polyprotein had InterPro domains that are shared by potyvirid polyproteins, including helicase, NIa protease, and RdRp domains. No HC-Pro cysteine protease domains were detected. Sequence similarity search revealed that the CeLV polyprotein (3640-aa, NCBI Acc. No. AZJ53460.1) was the most similar to the SaPIV2 polyprotein, with $44.9 \%$ identity in a 3917-aa overlap, whereas the other potyvirid polyproteins showed lower (15\%-20\%) sequence identities. Thus, SaPlV2 is the most closely related to CeLV among the currently known viruses.

CeLV is the sole species in the genus Celavirus (Rose et al., 2019). Because CeLV is distantly related to other potyvirids, annotation of proteolytic cleavage sites and mature peptides of its polyprotein is highly limited. The CeLV polyprotein was assumed to be cleaved into at least seven or eight mature peptides: one or two P1-like proteases, a P3-like peptide, CI, VPg, NIa-Pro, NIb, and CP (Rose et al., 2019). However, only two cleavage sites (NIa-Pro/NIb and $\mathrm{NIb} / \mathrm{CP}$ ) have been previously predicted. Therefore, the annotation of the SaPlV2 polyprotein is difficult.
The SaPlV2 and CeLV polyprotein sequences shared a strong sequence similarity with their $\mathrm{N}$-terminal regions (Supplementary Fig. S3). The SaPlV2 polyprotein was approximately 300-aa shorter than the CeLV polyprotein at the N-terminus. There was an in-frame stop codon upstream of the SaPlV2 polyprotein ORF, indicating that the SaPlV2 polyprotein was full-length. The CeLV polyprotein was predicted to contain a signal peptide at its $\mathrm{N}$-terminus (Rose et al., 2019). However, no signal peptide was predicted for the SaPlV2 polyprotein. Despite the difference in their N-terminal regions, it was assumed that the SaPlV2 polyprotein may be processed into seven or eight mature peptides similar to those of CeLV. The SaPlV2 and CeLV polyproteins lacked the HC-Pro segment. Among the six or seven potential cleavage sites, two were predicted in the SaPlV2 polyprotein: LNRQ/D (NIa-Pro/NIb) and QQIQ/N (NIb/CP) (see Fig. 2 and Supplementary Fig. S3).

A putative $\mathrm{GA}_{6}$ polymerase slippage motif for the P3N-PIPO fusion was found within the SaPlV2 P3-like segment (nt 2041-2047). A total of 191 purple witchweed RNA-Seq reads mapped to the putative GA $_{6}$ motif: 175 (91.62\%) were the wild-type and 16 (8.38\%) were the $+1 \mathrm{~A}$ insertion products, implying that the position was a polymerase slippage site. The predicted SaPlV2 PIPO contained 130 aa whereas the CeLV PIPO contained 189 aa. Sequence alignment of the SaPlV2 and CeLV small polyproteins with the P3N-PIPO fusion revealed that the PIPO segments of the two viruses shared many conserved residues, although their start positions were different (Supplementary Fig. S4).

\section{Phylogenetic positions of SaPlV1 and SaPlV2 among} potyvirids

To investigate the phylogenetic positions of SaPlV1 and SaPlV2 among potyvirids, polyprotein sequences of 76 selected potyvirids were collected from 12 genera of the family Potyviridae. In the case of the genus Bymovirus, which has a bipartite genome, two polyprotein sequences were concatenated. Multiple sequence alignment was generated using the MAFFT program, followed by filtering out the gap-rich segments using the trimAl program. A maximum-likelihood tree was constructed using the IQ-TREE program (Fig. 3).

SaPlV1 and BVMoV, the founding and only member of the genus Bevemovirus, clearly formed a strong clade with $100 \%$ bootstrap support. SaPlV2 and CeLV, the type species of the genus Celavirus, also formed a distinct clade with $100 \%$ bootstrap support. Phylogenetic relationships and similarities of genome organizations strongly suggested that SaPlV1 and SaPlV2 may be novel members of the genera Bevemovirus and Celavirus, respectively. 


\section{Conclusion}

In conclusion, the genome sequences of SaPlV1 and SaPlV2, novel members of the family Potyviridae, were identified from the transcriptome data of purple witchweed. Sequence comparisons and phylogenetic analyses suggested that SaPlV1 and SaPlV2 may be novel species from the genera Bevemovirus and Celavirus, respectively. The genome sequences of SaPlV1 and SaPlV2 may be useful for studying the evolution of potyvirid genome organizations.

Acknowledgments. This work was supported by the National Research Foundation of Korea (NRF) funded by the Government of Korea (grant number 2020R1A2C1013403) and the Chung-Ang University Research Scholarship Grants in 2021.

Supplementary information is available in the online version of the paper.

\section{References}

Adams MJ, Antoniw JF, Beaudoin F (2005): Overview and analysis of the polyprotein cleavage sites in the family Potyviridae. Mol. Plant Pathol. 6, 471-487. https://doi. org/10.1111/j.1364-3703.2005.00296.x

Bejerman N, Debat H, Dietzgen RG (2020): The plant negativesense RNA virosphere: virus discovery through new eyes. Front. Microbiol. 11, 588427. https://doi. org/10.3389/fmicb.2020.588427

Bos L, Diaz-Ruiz JR, Maat DZ (1978): Further characterization of celery latent virus. Neth. J. Plant Pathol. 84, 61-79. https://doi.org/10.1007/BF01976409

Bushmanova E, Antipov D, Lapidus A, Prjibelski AD (2019): rnaSPAdes: a de novo transcriptome assembler and its application to RNA-Seq data. Gigascience 8, giz100. https://doi.org/10.1093/gigascience/giz100

Capella-Gutierrez S, Silla-Martinez JM, Gabaldon T (2009): trimAl: a tool for automated alignment trimming in large-scale phylogenetic analyses. Bioinformatics 25 , 1972-1973. https://doi.org/10.1093/bioinformatics/ btp348

Chung BY, Miller WA, Atkins JF, Firth AE (2008): An overlapping essential gene in the Potyviridae. Proc. Natl. Acad. Sci. USA 105, 5897-5902. https://doi.org/10.1073/ pnas.0800468105

Crooks GE, Hon G, Chandonia JM, Brenner SE (2004): WebLogo: a sequence logo generator. Genome Res. 14, 1188-1190. https://doi.org/10.1101/gr.849004

Elangovan S, Srikakulam N, Pandi G, Jacob T, Ramakrishnan U, Madhugiri Narayanarao V, Tennyson J (2019): The first complete genomic sequence of cardamom mosaic virus, a member of the genus Macluravirus (family Potyviridae). Arch. Virol. 164, 1723-1726. https://doi. org/10.1007/s00705-019-04203-2
Gibbs AJ, Hajizadeh M, Ohshima K, Jones RAC (2020): The potyviruses: an evolutionary synthesis is emerging. Viruses 12,132. https://doi.org/10.3390/v12020132

Goh CJ, Hahn Y (2021): Analysis of proteolytic processing sites in potyvirus polyproteins revealed differential amino acid preferences of NIa-Pro protease in each of seven cleavage sites. PLoS One 16, e0245853. https://doi. org/10.1371/journal.pone.0245853

Goh CJ, Park D, Hahn Y (2021): A novel tepovirus, Agave virus $\mathrm{T}$, identified by the analysis of the transcriptome data of blue agave (Agave tequilana). Acta Virol. 65, 68-71. https://doi.org/10.4149/av 2021 107

Kondo T, Fujita T (2012): Complete nucleotide sequence and construction of an infectious clone of Chinese yam necrotic mosaic virus suggest that macluraviruses have the smallest genome among members of the family Potyviridae. Arch. Virol.157, 2299-2307. https:// doi.org/10.1007/s00705-012-1429-1

Mbanzibwa DR, Tian Y, Mukasa SB, Valkonen JP (2009): Cassava brown streak virus (Potyviridae) encodes a putative Maf/HAM1 pyrophosphatase implicated in reduction of mutations and a $\mathrm{P} 1$ proteinase that suppresses RNA silencing but contains no HC-Pro. J. Virol. 83, 6934-6940. https://doi.org/10.1128/JVI.00537-09

Minh BQ, Schmidt HA, Chernomor O, Schrempf D, Woodhams MD, von Haeseler A, Lanfear R (2020): IQ-TREE 2: New models and efficient methods for phylogenetic inference in the genomic era. Mol. Biol. Evol. 37, 1530-1534. https://doi.org/10.1093/molbev/msaa015

Nakamura T, Yamada KD, Tomii K, Katoh K (2018): Parallelization of MAFFT for large-scale multiple sequence alignments. Bioinformatics 34, 2490-2492. https:// doi.org/10.1093/bioinformatics/bty121

Olspert A, Chung BY, Atkins JF, Carr JP, Firth AE (2015): Transcriptional slippage in the positive-sense RNA virus family Potyviridae. EMBO Rep. 16, 995-1004. https:// doi.org/10.15252/embr.201540509

Palani SN, Sankaranarayanan R, Tennyson J (2021): Comparative study of potyvirid NIa proteases and their cleavage sites. Arch.Virol.166,1141-1149. https://doi.org/10.1007/ s00705-021-04997-0

Park D, Goh CJ, Hahn Y (2021): Two novel closteroviruses, fig virus A and fig virus B, identified by the analysis of the high-throughput RNA-sequencing data of fig (Ficus carica) latex. Acta Virol. 65, 42-48. https://doi. org/10.4149/av_2021_104

Park D, Goh CJ, Kim H, Hahn Y (2018): Identification of two novel amalgaviruses in the common eelgrass (Zostera marina) and in silico analysis of the amalgavirus +1 programmed ribosomal frameshifting sites. Plant Pathol. J. 34, 150-156. https://doi.org/10.5423/PPJ. NT.11.2017.0243

Park D, Hahn Y (2021): Identification of genome sequences of novel partitiviruses in the quinoa (Chenopodium quinoa) transcriptome datasets. J. Gen. Plant Path. 87, 236-241. https://doi.org/10.1007/s10327-02101002-z 
Revers F, Garcia JA (2015): Molecular biology of potyviruses. Adv. Virus Res. 92, 101-199. https://doi.org/10.1016/ bs.aivir.2014.11.006. https://doi.org/10.1016/bs.aivir. $\underline{2014.11 .006}$

Rodamilans B, Valli A, Mingot A, San Leon D, Baulcombe D, Lopez-Moya JJ, Garcia JA (2015): RNA polymerase slippage as a mechanism for the production of frameshift gene products in plant viruses of the Potyviridae family. J. Virol. 89, 6965-6967. https://doi.org/10.1128/ JVI.00337-15

Rose H, Doring I, Vetten HJ, Menzel W, Richert-Poggeler KR, Maiss E (2019): Complete genome sequence and construction of an infectious full-length cDNA clone of celery latent virus - an unusual member of a putative new genus within the Potyviridae. J. Gen. Virol. 100, 308-320. https://doi.org/10.1099/igv.0.001207

Seo JK, Kwak HR, Kim MK, Kim JS, Choi HS (2017): The complete genome sequence of a novel virus, bellflower veinal mottle virus, suggests the existence of a new genus within the family Potyviridae. Arch. Virol. 162, 2457-2461. https://doi.org/10.1007/s00705-017-3374-5

Shen W, Shi Y, Dai Z, Wang A (2020): The RNA-dependent RNA polymerase NIb of potyviruses plays multifunctional, contrasting roles during viral infection. Viruses 12, 77. https://doi.org/10.3390/v12010077
Spallek T, Mutuku M, Shirasu K (2013): The genus Striga: a witch profile. Mol. Plant Pathol. 14, 861-869. https:// doi.org/10.1111/mpp.12058

Valli A, Lopez-Moya JJ, Garcia JA (2007): Recombination and gene duplication in the evolutionary diversification of P1 proteins in the family Potyviridae. J. Gen. Virol. 88, 1016-1028. https://doi.org/10.1099/vir.0.82402-0

White KA (2015): The polymerase slips and PIPO exists. EMBO Rep. 16, 885-886. https://doi.org/10.15252/ embr.201540871

Wylie SJ, Tran TT, Nguyen DQ, Koh SH, Chakraborty A, Xu W, Jones MGK, Li H (2019): A virome from ornamental flowers in an Australian rural town. Arch. Virol. 164, 2255-2263. https://doi.org/10.1007/s00705-019-04317-7. https://doi.org/10.1007/s00705-019-04317-7

Yoshida S, Kim S, Wafula EK, Tanskanen J, Kim YM, Honaas L, Yang Z, Spallek T, Conn CE, Ichihashi Y, Cheong K, Cui S, Der JP, Gundlach H, Jiao Y, Hori C, Ishida JK, Kasahara H, Kiba T, Kim MS, Koo N, Laohavisit A, Lee YH, Lumba S, McCourt P, Mortimer JC, Mutuku JM, Nomura T, Sasaki-Sekimoto Y, Seto Y, Wang Y, Wakatake T, Sakakibara H, Demura T, Yamaguchi S, Yoneyama K, Manabe RI, Nelson DC, Schulman AH, Timko MP, dePamphilis CW, Choi D, Shirasu K (2019): Genome sequence of Striga asiatica provides insight into the evolution of plant parasitism. Curr. Biol.29,3041-3052. e3044. https://doi.org/10.1016/j.cub.2019.07.086 


\title{
Two novel poty-like viruses identified from the transcriptome data of purple witchweed (Striga hermonthica)
}

\author{
Dongjin Choi ${ }^{1}$, Chaerim Shin ${ }^{1}$, Ken Shirasu ${ }^{2,3}$, Yoonsoo Hahn ${ }^{1^{*}}$
}

${ }^{1}$ Department of Life Science, Chung-Ang University, Seoul 06974, South Korea; ${ }^{2}$ RIKEN Center for Sustainable Resource Science, Yokohama, Kanagawa 230-0045, Japan; ${ }^{3}$ Graduate School of Science, The University of Tokyo, Bunkyo, Tokyo 113-0033, Japan 


\section{Fig. S1. Alignment of the polyprotein sequences of SaPIV1 and related viruses \\ Putative cleavage sites are marked by vertical bars (|) and highlighted in yellow.}

Striga-associated poty-like virus 1 Artichoke latent virus (YP 009129267.1) Narcissus latent virus (QDC21212.1) Broad-leafed dock virus A (YP_009507671.1) Crow-dipper mosaic virus (QGV12925.1) Alpinia oxyphylla mosaic virus (AW077093.1) Cardamom mosaic virus (YP_009508901.1) Yam chlorotic necrosis virus (AZQ00683.1) Chinese yam necrotic mosaic virus (YP_006590058.1) Bellflower veinal mottle virus (YP_009508455.1) Yam chlorotic necrotic mosaic virus (YP 009507672.1)

\begin{abstract}
-MDYLALTRI -VANRQTIDMP - - - -RVLELAIKEVYGTYNRELNSA - - - IDFKGEQLETTPAT - - - TDPLDVFIK MATVKA-NV-NFKVDNVDTLNTHLMOLMSGSALKIOPLTAAALMRMVDRHFEANAMIKGSEFIMVDGGGKTLATFNTSMRNNANLETFMK MATVKS-SV-NFKVENVDTLNTHLMOLMSGNPLNVPPATARALLELANKRFETNKMAKGSEFLMVDGDGKTVATFNKAARNNADLRTFMD MATVKS-SV-NFKVENVDTLNTHLMQLMSGNPLNVPPATARALLELANKRFETNKMAKGSEFLMVDGDGKTVATFNKAARNNADLRTFMD
MAKSSN-DV-AFKVENVDTFNTHMLQLITKNELGILPETLKVLTAIIERRYEVCSMKDPRDFMMVDGKGKLLARFSQLRGREMTLKEFLS MASASKLEV-NFKVDNVDTLNTHVLQILSGKSLTMPEKTKEAL IECVNKKFETFNGDTSKDFLMVDGKGVVLGKFQNFDARNINLKTFLE MASNSK - IVSNFKVEVVDFLNTHAAQITTGKNLNIEDKTRSKVVAFVRKQYINNELKDGKDFVMIDGKGKTVANFPTTVRGTTKLKDFLT MASGKK - QLGNFKVEVLDVLNTHMAOMLMGKTLSVEERTREVLVOIVKKHYRKNEMKEGGDFVMVDGKGKTVASFPTLLKGKPTLKDFVD MATVKP-DV-NFKVELVEFLSTHNIQMMTGNPLTIPDKTRAKLVDFVKRFYEINKGEQAKDFVMLDSKGKTIASMPMAVTSSTKFKTFLE MATVKS -DI -NFKVENVDILSTHSMQMLTGKPLTIPDRTRALLVEIVGKRYQNNDGNTSADFVMLDGKGAMIANMCMAITKGMKFKDYKD MATVKS -DV-NFKIENVDILSTHSMQMLTGRPLTIPDKTRAQLIDIVARRYQENGGTNSSDFVMLDGKGVLIANMCMAITKQTKFKDYKD
\end{abstract}

$$
:: \text { : }
$$$$
*
$$

NELKEINDAA-GDCGKIA-CVR--PRTLPEGFYATMSYAMGGLKGVIPGPVSKRRCFRDGYCYMNIFVAIAPHVYDEDALVYAKFLNDCP GEIKFPAOOSFELCDKIVKCTKMHOOHVAHTRLPAAGYTFGGYSKLCPIPLYOGHVAKOGHCFKTLMLAISYFVTKEFDGVFAGIMDEVT SKIAFPAQQSFELCDKIIKCTKMHOOHTAHARLPSVNYAFGGYSKLCPIPLFKDKVAKOGHCFGTLLLALSYFVTKEFDDEYAKIINEIV QSFSVPAQTSFTACDKVVKCVKGHQQQLAHLRVPSVDYVFGGLSRVCAIPLIKNRVAKQGNCFFNALIAISYFIRQEDDIMFANIVKELD KTTPVPAQESFKKCDKIIKCTKVHQQQMAHMRMPSMNFVHGGISKVCAIPLIVNKIARQGNCIYNALMAMSYFVRE EDDELYASIVKEVL AKFEIPDEQSFERCDKIIKCVKAHQQQMAHMRTISNDYAFGGLSKICPIPMIKGMVPNQGMCFLTLLISTSYFITPELDEQFSLVIDEVL KEFQIPAQQPFNTCDSVTKCIKAHRQQLAHMRTISSDYTFGGISKICPIPLIQGMVPVQGMCFFTMVVSLSYFIPPELDDKFAQLLEEIL AGLRLPAOASFLGCDKVVKCIKTOQOHLAHIRLASNDYVFGGISKSCPIPMIKGMVPKPGFCFLNI IVALSYFVTAEFDQVFESTIDDVM GMVNMPQQTSFAECDKVVKCVKVQQQHLLHARLPTNDYVFGGMSKSNAIPMIKNMVPKSGSCFLSAIVAMSYFVTPEFDEIFMQTINDVL GNISMPQQGSFADCDKAIKCVKVQQQHLLHTRLPANDYVFGGMSKSNAIPMIKNMVPKSGSCFLSVIVAMSYFVTPEFDEIFVETVKDVL AGMKFNDDVA-GECPKGQ-CNEASKGRSSWFLNCSPTLAVGGRSATF IMPMSPRRVFSSGYCYLNLAVAMSPYIFDEDAIKFAEFLHDLP

63

Striga-associated poty-like virus 1

Bellflower veinal mottle virus (YP_009508455.1)

Artichoke latent virus (YP_009129267.1)

Narcissus latent virus (QDC21212.1)

Broad-leafed dock virus A (YP_009507671.1)

Crow-dipper mosaic virus (QGV12925.1)

Alpinia oxyphylla mosaic virus (AW077093.1)

Cardamom mosaic virus (YP_009508901.1)

Yam chlorotic necrosis virus (AZQ00683.1)

Chinese yam necrotic mosaic virus (YP_006590058.1)

Yam chlorotic necrotic mosaic virus (YP_009507672.1)

Striga-associated poty-like virus 1

Bellflower veinal mottle virus (YP_009508455.1)

Artichoke latent virus (YP_009129267.1)

Narcissus latent virus (QDC21212.1)

Broad-leafed dock virus A (YP_009507671.1)

Crow-dipper mosaic virus (QGV12925.1)

Alpinia oxyphylla mosaic virus (AW077093.1)

Cardamom mosaic virus (YP_009508901.1)

Yam chlorotic necrosis virus (AZQ00683.1)

Chinese yam necrotic mosaic virus (YP_006590058.1)

Yam chlorotic necrotic mosaic virus (YP 009507672.1)

Striga-associated poty-like virus 1

Bellflower veinal mottle virus (YP 009508455.1)

Artichoke latent virus (YP 009129267.1 )

Narcissus latent virus (QDC21212.1)

Broad-leafed dock virus A (YP_009507671.1)

Crow-dipper mosaic virus (QGV12925.1)

Alpinia oxyphylla mosaic virus (AW077093.1)

Cardamom mosaic virus (YP_009508901.1)

Yam chlorotic necrosis virus (AZQ00683.1)

Chinese yam necrotic mosaic virus (YP_006590058.1)

Yam chlorotic necrotic mosaic virus (YP 009507672 .1)
LVLGSWPTMNSLAKAMIWIGQKIPNLYNKAVPAVSISHTAEACHVVDQRGPVKGWHILDAPTFRDVILFSL - KSDLSEYIIG|G-DPVT IVLGKWPAMVKVARSFAWLLQHMPYLCDRHIPHIS INHNLNAAHVSDQRGPMIGCHILNAYTLKDFVLTGM - -DTLNANTMLG|GMDALT SNIKSWPSLKDVSKICQYIISKVPILGPVPIPVVAVDHAKKLIHICDQRGIPDGWHQLKMGTLAELANAGLLSQSSLHTFFVG |GDAQQP SFLGAWPKLAQIAKICQYIIMRVPILAPVPIPVVAVNHEKSLMHICDQRGIPDEWHQLKMGTLAELANAGLLSSSKLCSYYVG|GTDE-AVITSWPKLSDVSVYLQYLIAKLPYLGAMPIPAVAVSHERKLIHFCDQRGVPHGWHVMKMGILAEAANAGFMKGSGI PNYYVG|GTHE- ADGTAWPKLERVSKMMHYIIMKLPYLAAAPMPAIAVDHERSLIHICDQRGVPQQWHVLKIGTAAELANAGLMKSSNLINYFVG|GTNQ- SEMKPWLTLQTASKIVQYIICKIPVLAHVPIPAVAVDHMKSLIHVCDQRGVPSGWHVLKIGTLAEFANIGIIENSKLTSYFVG|GSEKND QLLKAWPTFETVAKIAQFIIYRIPILAHVPIPALAVDHENGLMHFCDQRGVPAGWHVLKIGMLAELANAGTMTTSKLNKYYVG|GSNEGQ RELGPWPKLEAVSKAVOFIIAKVPILGPVPVPS IAVNHEDKL IHICDORGVPNGWHVLKVGTASELANAGL IKGSSISNNFVG |VFGDAP GELGSWPTLQNVSKAMQFILAKVPTLSMVPLPVIAVTHEKKLIHICDQRGVPNGWHILKIGTVAELANAGFIKHTKLNGYFVG|APESIT HELGSWPTLKNVSKAMQFILAKVPILGMAPLPVVAISHEKKLIHVCDQRGVPNGWHILKIGTASELANAGLIKNSKISDHFVG|STEDVR

AAYMHLSKCIRHANNTRQPWVT- - -FNKMVLEDSALAATLVLSPATLIKLESWFEDREEFRRLVATIESGVGDALTRIIVIKRAIEGVKI SAYQSLDKAIMQANKSFQPWLT - --FYRMICADSMLAATLIMSPATLQKLESWFEDDEGFRRVVATLETTVSDALLRMVIIKRAIHGVKM EE-MLYLRGLSKVKANLRTWVTKGTMVDDLARDIDLAAFMMLSPVMLSRLRTLIEREEASAMKAIVMDSSCNNKLVVASALRTAVQGVLV DKTELYRRGLSKVKANLTRWMSKGTMIDDCTRDLDLAAFIMLSPNMLSRLRSLVERDDDAAMKAILMDASCPNKLVVASAIKTAIQGVLV TTVQLYSNOLAKVQGKLKGWIRSGGLFEDLVKDTOLAAFVILSPALLSRLONLIESEASAVVSIEKLEAAHENKVVAMTAVRTALTGVRI EIVELYSTQINKAKQLLPKWIKGGDIFDDITKDVNLAAFMMMSPSMLSKLQNVIHTTASEALNLEKLETSHENKIVAINAIQAALAGIRV DELQIYVDQLTKIKKNFKEWVLKGNLFETLKNDMLLTAFLVLSPAHLSKLHNFLESNANEALQICELDTVNKNKILAATIISTGLKGVRI DDLDFYVEQIHKIKKNFSRWLTSGTLFSDLANDVHLTAFLALSPAHLAKLHHYLEISAEEAQKIVQLDAVNKNKIMAAAVIQTALKGIRI EERVFYVENLTKVKHALTKWRKPEAFLNALTQDINLMSFLLLSPSLLVKLQRTLEKGANEALMLDVIERSTSDKIVTANLIKAALEGITV DDKMFYTRNINKVKNLMTLWRSPERFVEAMANDIELTAFILLSPSLLSKLYNLLSIGSSEALKIEALERANSNKIVVASLINIALQGVRV EDKMFYNRNINKVKSLMQLWKSPERFVDGMANDIELAVFIIMSPSLLAKLYNLLSKGASEALRLEALERANNNKIVVASLINAALQGIRI 235 241 267 265 265 266 268 268 268 267
267 267

322 328 356 355 355 356 358 358 357 357 357

HFLDNDIETATAALHORVLEYIRNADD - -GGALNAAATRFSNLVTEKKEOFYYFEKRIHSLSDFRWRREHDFGVISIGESCCTGAIHMLR HFRTDNVERSTNELHRAIIAYIDSQDDQSAKDLGDAARRFETMALEKKMQFVYLESSIAHCSDYRWRRERGFSYISCGESLCTLLLSKLG HTGETRIERIWLQVNNVLQDHLNSEGKEIEVALSRALHRLHNHLMSEKKLIFSYERRLNLLTHDQFKLEFGCSHGWGSKFYYMLAGRNGE HTNETKLEKIWTNVNNVLQDHLAAGGREIDRELSRALHKLHSYLLHEKKT IFSYERRLYALTATQFRQEFGCSCGWGGKLLAMAFKQNGS KSGDKDIEKIWHHIHTLMMMGIYDGEESHYKGEMRQAVTNLYYTTLVAEKKYVTACERALYSATEEEFAKSFGCOPTWYDKFSFTAWRESRR RAGCSDIEKVWLHIHS IMMNHFDEEENKFKAEMRLAVTRLYAAMIAEKKYVTSCERAIYRTTKEEFLKNFGLOOGFVSKLSFTHWRNRRS KWRETSCEKLWLHLLKTIEAVLEADDTQQATNLRSACERMYEVMCANKKFVYCCEKRIYYLTDAEFQTTLGFSPTWFGALQARLGFTRAS KLRETDIEKVWLHLHKTLDHILQDDDSDASARLREACTRMYNVLCANKKFVYQCEKHTYSRDNATLREMFGCSSTWLSRLQRKLHILSGE KLGETQLEKVWLHLLEVVRVQLDYDECQRNKDI IDACGMVYNQLCKEKKSIYHYEKQIYHMDEREFQRTFYYSPLSLGEAVSGF INTKFG KMGETSLEKVWLHLLNVLTANLSIEESRRNTDILQACNAVYNELIKEKNYMYHCEKQIYNLTDKQFEDMFGCSRTWHSKLCDKLSHLNVA KMGETSLEKVWLHLLNVLTANLSIEESQRNNDILKACNMVYHEFVKEKNYMYHCEKQIYQLTDKQFEDMFCCSHTWQEEFCRKLSHLNII

410 418 446 445 445 446 448 448 447 447

NTL--PYLEKLEAKEK- SCI - PAIOLOEORERLP - . - . - - - - - - EFIRAARYTWVTIYWFVOAASLMLLGWFSIKNFMLFLLRAVTKYYLGHHYAHHIWT TDVGKSSISYKIFNDGITHRTIEAINAYFIISTVCVINTLNALFGLVQFAFYIMLMCF -GFMSLTKFMFHCAKALLIRRLATNWER - - M VDVGRSAISLRAFDDGI THRT IEAVNLFFLISTFHIFRALSYIFVITRILFYIFLTAF -GCMSLSKLLFHLAKAMLIRRLAHNWER - - - L GYVGAPRIKLQSLEDGLTGVACQFLSSLGIQMVLGLINTGCKCYSLAKF ICYIFLLIW -GSLSLSKFMLFCMKQLIVRKFSNNYKK - - - L SGLGYSNIKLKYLEDPINSAFANHMSRVVMLLMLGVVKTGSQLFSVTQFFFYIFLVMW -GSMSLSNFIFYMFKSVVISRLSGNYKK - - - L DSLTVSKIRLSCFSDNIVYRTLPYVNAFFLYFTIOLFATMSYLFSVARIIFY-CIFVWHGIFSISSLVLMLVKSLIVSRLSRNYNK - - - L RQLVVSNIKLACFSDGIIHRTIPYVNAFYLYFTINLFAFLSNIYSLARLFF - LFIFAWYGCVSLTSIVFHLIKMLVLSRLSRNYNK - - -V NLLAKPRLRLNCFSDGIDRYSFGPFLNIMNITIIKLLLFAGRMYNLFRVFFCLCAFCW-GFMSLGNLAYIAFKTAVLRRLSGNYEK-- - L KSVQQSSVKLSCFSDGITHRTIQAVTHHF IMCF IRLLIFAQHAYSILRFFFLLAACCW - GFMSITNLVFMAFKAVVMRKLATNYEK - - - L KSVQQPSVKLLRCFDDGITHKT IQLVTQHF IICFVRLLIFAQHTYS IMRFFFCLCACCW-GFMSITNLVFMAFKAVVMRKLATNYEK - - -L
482 490 532 531

8

\begin{tabular}{l}
7 \\
767 \\
767 \\
767 \\
\hline 67
\end{tabular}

72
5
5
5
5
5
75
75

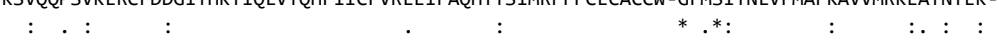


Striga-associated poty-like virus 1 Bellflower veinal mottle virus (YP_009508455.1) Artichoke latent virus (YP_009129267.1) Narcissus latent virus (QDC21212.1) Crow-dipper mosaic virus (QGV12925.1) Alpinia oxyphylla mosaic virus (AW077093.1) Cardamom mosaic virus (YP_009508901.1) Yam chlorotic necrosis virus (AZQ00683.1) Chinese yam necrotic mosaic virus (YP_006590058.1)

Striga-associated poty-like virus 1

Bellflower veinal mottle virus (YP_009508455.1) Artichoke latent virus (YP_009129267.1) Narcissus latent virus (QDC21212.1) Broad-leafed dock virus A (YP_009507671.1) Crow-dipper mosaic virus (QGV12925.1) Alpinia oxyphylla mosaic virus (AW077093.1) Yam chlorotic necrosis virus (AZQ00683.1) Chinese yam necrotic mosaic virus (YP_006590058.1) Yam chlorotic necrotic mosaic virus (YP_009507672.1) Broad-leafed dock virus A (YP_009507671.1) Yam chlorotic necrotic mosaic virus (YP_009507672.1) Cardamom mosaic virus (YP_009508901.1)

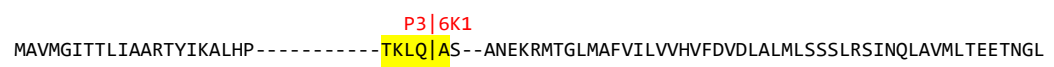
LLISTIALLVSAWTYMKATKP - - - - - - - -TQLQ| AT - - TNEKKVTGLIAF IVLAVHIFDADLAIMLSSSLHTISRTASMLTDETRNI MIITSIFLIYELSRFIMKKKAEREKLNEGRS-EELQ|ASVKSSEKOMMAAMAMMTLVVHAFDIDLAITMSGALNHVARLANMLTDTTSGW MIVTSIFLVYELARFIIGRKATRQKNVHSKD -QELQ|GPHKSSEKQMMAAMAMITLIVHAFDMDLAITMSSALNHVSRLANMLTDTTSGW VLFGTLFVIYELATYVARKMKQRKEKGDG - - - QELQ| LNSKENEKKMMAAMAMITLFVHAIDMDLALVMTSSLNHVARLVGLLTDSTTGW MLLGSVFVIYELAMYIKRELAKKRDGK - - - - -QTLQ| FKGKESEKKMMAAMAMATLAVHAFDIDLAIMMSNSLHHVSRLVSLLSDSTTGW LICGTVFCVFELGRYIIKQKQRKNQIQP - - - - HELQ| AGLKTSEKQMMSAMAMLTLLVHAFDMDLAVMMSNSLNHVARLANMLTDTTSGW LFCGFVFCMFELGRYIAWKKSQRKENQP-----QELQ|ASIKSSEKQMMSVMAMITLLVHAFDIDLAITMSNSLNHVARMANMLTDTTAGW LIFGCVFALYEVGSFI IKKRKEROOKLOTKEGEILO|AYGKSSEKKMMSAMAMITLIVHAFDMDLALMMSNSLNHVARLANMLTDTTSGW LIFASIFCLYEVGRFIIKKRKANKDKAAGRT -TELQ|AYGKSSEKQMMAAMAMVTLFVHAFDMDLALMMSNSLNHVARLANMLTDTTTGW LIFACIFCLYEVGCFI IRHKKKSKELGTGKT -QDLQ AYGKSSEKQMMAAMAMITLFVHAFDMDLALMMSNSLNHVARLANMLTDTTTGW ** $\quad . * *:: .:^{*}: *^{* *}::^{* * *}::::^{*} .::::^{*}:: * *$

$6 K 1 \mid C I$

LPKLIG-TRLQ| FDESDLA-DLELEMDPEEVRNETLQEKCMTFGMWLETKVASYVDYTRELQYGGPEVHYRISPLKQQEIAEDMTQTKRA LPRIINGTVLQ| GDIGEI -MELDVEIDPEIAQHEELRTKHKTFQAWIDEKVCSLEQYTRELQYGGSSVHFVVHSSNHDDISDDMLATKRE LVGGTATEELQ|MHIFDVALEVDEQQKMEGEMMASTSSSLDTFSAWVNESVATGVDNTRPLTYGSVDNVYKLDSENGAEVGASMTNTKKA LMGGTATEELQ|MHLFDVALEVDKQQQIENEMAASSSNLADTFSAWINENVAYGTDNTRPLTYYGDVENVYKLDSKNGSNVGATMVNTKKA LVGG-GRQELQ| MKIFDLALEVDDTMKADEEVAATTSNHQDTFSAWVNEQLVLGNDNTRPLSYGRTDSLFTLTSDNATEVGQNMVDTKRA LVRGGSHQELQ| MKFFELALEVDDKVKQENELEAQTSTSMDTFASWINEQIAMGNDNTRPLVYGRNDEIYKLNKENASEVGATLTQTKRA MMGGTGTQELQ|MELFDLVLEADEKIQSDLEEAVTSHRTCETFASWMSEQSLTESNNTRPLSYGRPESYVCVDRENAVEIGQNLVDTTNA VMRGNDSQELQ|MQLFDLALEADDTIRNELDEASTSHTTYETFSSWMAEQTLFENDKTRPLSYGRVESLVEIDRDNAVESGQALVDTTNA LIGGANTQELQ| MRLFDVVLEVDEVMEKEIQQTSVYEGGTETFSSWINEQIALGNDNTRPLAYGRDESVFFVDRENAIQVGQDMVETRNA LTSGGGTQELQ| MKLFDVALEVDETMTHEMDQQAAMDCSNETFAAWINEQVLLGNDNTRPLAYGRDDSVFYVTRDNAIDVGQDMCDTKNA LTSGGGTQQLQ|MKLFDVALEVDETMSNEMEQQAVHDCSNETFASWINEQILVGNDNTRPLAYGRDDSVFYVTRDNAIEVGQDMCDTKNA$$
\text { ** } \quad * \quad . \quad: \quad * * * * * \quad . \quad: \quad: \quad: \quad:^{*} \quad * \text {. }
$$

WNSVTGGTGSGKSTRIPVFYYQRLKQMADRNKRILVCEPSRATVVNVAAGISSFLGEQVYYKHRTKEQAGNMGIQVMTYGSALMRAVGDS WNSVVGGTGSGKSTRIPVHYYNKLQKAIGRQHKILICEPSRATTANVAMGITHFFGQQVYYKHRTREQVGHMGIQVMTYGSALMRSLRDP WSHVVGKTGSGKSTRVP LGYYNALQTMAARRRNILICEPTQATTQNVANALSHFHGKSVFYKHEGKEQMGDMSIQVMTYGSAFFRSVHNP WSHVVGMTGSGKSTRVPLGYHGALOTIAARKRNILICEPTOATTONVAAALSRFHGKOVYFKHEGREQLGDMSIQVMTYGSAFFRSVNNP WSLVVGQTGSGKSTKVPIAYYNKLQIQAGRRKNILVCEPTQATTQNVASALSHFHGKSVYFKHEGKEQHGDSSIQVMTYGSAFFKSVNNP WSQVVGQTGSGKSTKVPMSYYNTLQTIAGRRKNILICEPTQATTQNVAAALSHFHGKSVYFKHEGKEQHGDTSIQVMTYGSAFFRSINNP WTQVIGQTGSGKSTRVPIAYYNRLQHLPARRRSILVCEPTQATTQNVSYALSHQHGKQVFYQHEGKTQNGDSSIQVMTYGTAFFKAMNSN WTQVVGQTGSGKSTRLPIAYYNRLRHVAARKRAILICEPTQATTQNVAYSLSHQHGKQVYYQHEGKIQNGDMSIQVMTYGTAFFKAMSAD WSQVVGQTGSGKSTRVPLAYYNKLQTMPGRARSILICEPTKATTQNVASAISHQHGKOVYFKHEGKEQTGDPTIQVMTYGTAFFRACNNP WSQVIGQTGSGKSTRVPLSYYNKIQTLPGRNRSILICEPTKATTQNVAAALSTQHGKQVFFKHEGKEQAGDPTIQVMTYGSAFYRSCNNP WSQVIGQTGSGKSTRVPLSYYNKIQTLPGRNRSILICEPTKATTQNVAAALSTQHGKQVFFKHEGKEQAGDPTIQVMTYGSAFYRSCNNP
WSQVIGQTGSGKSTRVPLSYYNKLQTISGRCRNILICEPTKATAQNVAAALSTQHGKQVFYKHEGKEQAGDPTIQVMTYGSAFYRSCNNP

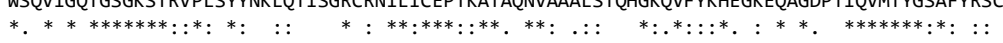

NFLNSFDAVFLDESHIVSEHGLTLEALLDGYRHVRKFYVSATPRAGPFEDNGHKRFQTQRVDVENSDPNYWLKEQGRGTAYDVTKRGPVV HFIMOFDAIFFDEAHFVSAHALTLESLSKOYPEVRKFYMSATPRVGVTPHOAKGRFNTEVREVENTDPNFWLKEOGTGSRYDVTSLGPVI TFLDDFDAVF LDESHLITPHSLALESLLNKHTKVRKFYLSATPRNGISCDDVARRFQIYEHTVEKCSVDEF IAQLDKGTATDPMKYGDKV TFLDDFDAVFLDESHLISPHSLALESLLNKHTRVRKFYLSATPRNGILCDDVKRRFEIHEHAVEACDLEQFIMQLGKGTATDPMQFGDKV SFLSSFDAVFLDESHLISPHSLSMEGLLNKHTEVRKFYLTATPRDRTLQQTVNRRFQIFEHQVEKADVAEFIAALNGKTNLDALQYGERV GFVDGFDAVFLDESHLVTSHSLAMEAILNKHTTVRKFYLSATPRIPVDVTHQDRRFQIYEHTVEKADVSDFFIAALNGKTILDALEYGDKV EFIEKFDAVF LDESHLISAHSLAFESYLNKCTTVRKFYLSATPRTSCSMPDASRRFEIYEHSLPETDINTFVASIGKGDSLDALNYGEKV TFIQOFDAVFLDESHL ITAHSLALESYLNKCVSVRKFYLSATPRNHVPTNATVRRFOIFEHAOPEVSIEAF ISS IGKGDSLDALNYGEKV VFLDGFDAVFLDESHLISAHALALESLLNKQTHTRKFYVSATPRRQVNQPQGTRRFQIFEHHVETADLNDFISSLGKNGNLDATQFGDKV AFLSNFDAVFLDESHLVSAHALALESLLNKNNRVRKFYLSATPRKQFPEMTGSRRFEIFEHQVESGDVNDL ISAIGKGTIMDATKFGEKV AFLSNFDAVFLDESHLISAHALSLESLLNKNNRVRKFYLSATPRKSFPQQTGTRRFEIFEHQVESGDVSDLISAIGTGSILDATKFGDKT $*: * * *: *: * *: *::: *^{*}:: *, \quad . * * *:: * * * * \quad * *: \quad: \quad * *^{*}$

Broad-leafed dock virus A (YP_009507671.1)

Crow-dipper mosaic virus (QGV12925.1) Alpinia oxyphylla mosaic virus (AW077093.1) Cardamom mosaic virus (YP_009508901.1) Yam chlorotic necrosis virus (AZ000683.1)

LCFVOGRGOADKLAAKVNNSSIRDEKGEKFTGYSLHSENFDDNYPKVIKASNEGETCFIFCTNILETGVTLSADCVVDFGSTMRPELDIM LCFVQGKRQADTLASKVNASG - - - - -KIQFKGISLHSDNFDNNYNLVVKATNEGEECMIFCTNILETGVTLNADCVVDFGFTMRPSLSVA LVFLAGKGECDKAASKVMSTN - - - - - LGIKAVSLHKSNFKTNYVKVMNSVDGGDRVIIFATNILETGVTLNVDVVVDFGFTNSPVLDLT LVFLASKSECDQAASRVMSMN - - - - - - LDVKAMSLHKDNFKTTNYLKVVAAMDESAKVMVFSTNILETGVTLNVDVVVDFGWTNRPPHLDLT LVFLSGKNECDRAAAKVAGGV--- - RGVKSVSLHKDNFKANYQKIIDQLERDEQFVIFTTNILETGVTLNVDVVVDFGYTNSPVLNLV LVFLSGKNECDKAAAKVNGGV - - - - - - KGVSAISL LKDNFF INYAKVCOOLEMDGKYMIFATNILETGVTLNVDVVVDFGYTNVPDLNLS LIFLSGREQCNKAAHKTASTQ - - - - - - YGITAFSLHKENFSVNYSKILQALSQPGRVYIYSTNILETGVTLNVDVVVDFGYTNQPHLDLN LIFLSGREQCNRAAMKTAATQ-- - - - -YGIRAFSLHKENFPSNYPKILDALSAPGRCYIYATNILETGVTLNVDVVVDFGFTNQPKLNLT LVFLSGKKECDRAAARVCAEV - - - - - - SSLKAISLHSQNFE TNYERICDQLNQPGKLIIFCTNILETGVTLNVDVVVDFGFTNTPSLNTV LVFLSGKKECDRAATKVNSTN - - - - - SGVKAISLHRDNFSANYNRLCHDLTQPGKIYIFATNILETGVTLNVDVVVDFGFTNTPVLNTS LVFLSGKKECDRAAAKVNSTN - - - - - TRVKAVSLHRDNFSTNYNRVCDELNQPGKCYIFATNILETGVTLNVDVVVDFGFTNAPTLNTT 825 834 889 888 885 885

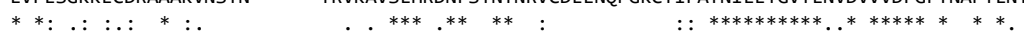

TKRLSLNAHRVTQFERHQRIGRVGRVKDGFALCCGKAVHGRPRTPPEVVYGAALYSFVYDLDLFADESLDTSWLANITKKQAEVMLSFDL 1005 EKRCLLTSSRVTQHERLQRIGRVGRVKDGVALTCGKCLPGRPPISPDVVYEAALYAFLYDLDLYADSTLDTNYLGNITRQQAEVMLNFDI 1009 GKTFLLERRRVTQAERKQRIGRAGRLRDGHAIVIGKVGGTEELVSADVVYEAALISFVYNIDIYINSHFDHVWIGNVTRQQAKTMINFRL 1063 EKTFLLHRORVTKAERKORIGRAGRLKEGHAIVVGTVSHNVELAPADVVYEAALLSFVYNLDIYVNSHFDSVWVSNITRAOARTMLNFRI 1062 EKTLLLRKRRVTDAERRQRIGRAGRLRDGHAIVVGKTVQATELVAADVVYEAALLSFVYNLDVYINAHFDHSWLAGITRAQAKTMLAFRM 1059 DKTLLLRKRRVTKAERQQRIGRAGRLRDGHAIVIGKTTEPMEIIPANVVYEAALLSFIYNLDIYINTHFDHTWLSSITRAQAKTMANFRV 1059 ERTLLLQKRRVTESERKQRIGRAGRLKHGHAIVLGKTSRAIEVVTADVVFDAALLSFVYNLEVYVNTHLDSTWLAKITREQARTMLSFRL 1062 ERTLLLEKRRVTEAERKQRIGRAGRLRDGHAIVLGKTCQAIEMVTPDVVFDAALLSFVYNLEIYVNAHLDCEWLATITREQARTMLNFRL 1062 DKTLLLHKRRVTKSERQQRIGRAGRLRNGHAIVIGKVSEPIETVSAEIVFEAALISFVYNLDVYVNSHFDAAWLGSITKEQARTMLSFRV 1065 DKTLLLNKRRVTQAERKQRIGRAGRLREGHAIVIGKTSTPFETVSADVVFEAALLSFIHNLDVYVNAHFDQAWLSSITRDQAKTMMAFKI 1064

Chinese yam necrotic mosaic virus (YP 006590058.1)

Yam chlorotic necrotic mosaic virus (YP_009507672.1) DKTLLLTKRRVTQAERKQRIGRAGRLKDGHAIIIGKTSTPFEVVSADVVFEAALLSFIYNLDVYVNAHFDQAWLSSITRDQAKTMMAFK

Artichoke latent virus (YP_009129267.1) Narcissus latent virus (QDC21212.1) Broad-leafed dock virus A (YP_009507671.1) Crow-dipper mosaic virus (QGV12925.1) Alpinia oxyphylla mosaic virus (AW077093.1) Cardamom mosaic virus (YP_009508901.1) Yam chlorotic necrosis virus (AZQ00683.1) Chinese yam necrotic mosaic virus (YP_006590058.1) Yam chlorotic necrotic mosaic virus (YP_009507672.1) PMYVLRDLVDKDGSMOPIMVSLLKNHVVGDTOITTRDVRVSADKWASWPNAHDLIMLCLRGSEDEEMMKLAKEKIPFCAYOLLDVDLKSF PSFAMKDVVFPDGSVRDEFLRAVKDRTNRSANIKTLOGCTINPVYEGWPVLGTYAOKFGIAFEDSRYNNLSKMRVPFIFHDMNELDIEAY PSFAMKDVVFHDGSVRTEFLEOMKSYTQRSANIKTTTHCTINHVYDTWPLLGTYAOKFGISFDDARYRKFSKLKVPFIYHEMGSMDLEGY NSFFMRDLVFSNGSVRPELLQALKNNVQRSSNIKTATMQCVSHVYESWPMLGAHA- - - - - PVDNLDEKLVKSRVPFITHDLFEMQVEEL SPFVMRDLVFADGSVRPEVLSLFKKETMNSTSIKTRSATHVSHITEAWPKLGAHI - - - - - PQGETFNPLSDKRVSFITHDLLEMDLDEV 1143 STFFMRDLVNSQGHIRPELLDALKNKTWRSLKAHTTMFQARNSEYQQWQRLDHYSFSTLVLNNERILSEVGHVKIPFITHDMMDFDIIEI 1152 SVFFMRDLVNKOGNIRSELLQAVKNKTWKSLKVHTTNFOANNREYOOWNRLDHYTLTNFCAENSOAFGEISHIRVPFITHDMLDFDLVEI 1152 SPFIMRDLVFPSGHVRQEMLNCLKNKLQRSASIKTANYTCVNHIFESWPKMDHPFISTIVQNEPNSLERLSKLRTPFVTHDMGELNLEEF 1155 SPFIMKDLVFANGHIRSEMLEFLKPHLHHSANIKTTNYQCVNHIYESWPRLDHHSLIDSMQNNEEKTKKIHKMRTPFITHDLNQLDLEMF 1154 SPFIMKDLVFANGHMRGEMLDFLKPHLHHSANIKATNYQCVNHIYESWPRLDHHSLFLDSQAHDSEVKRLSKMRVPFITHDITQLNLEQF 1154 
Striga-associated poty-like virus 1 Bellflower veinal mottle virus (YP_009508455.1) Artichoke latent virus (YP_009129267.1) Narcissus latent virus (QDC21212.1) Broad-leafed dock virus A (YP_009507671.1) Crow-dipper mosaic virus (QGV12925.1) Alpinia oxyphylla mosaic virus (AW077093.1) Cardamom mosaic virus (YP_009508901.1) Chinese yam necrotic mosaic virus (YP_006590058.1) Yam chlorotic necrotic mosaic virus (YP_009507672.1) Yam chlorotic necrosis virus (AZQ00683.1)

VEAAATYEPKLSFKTTKLGPPTRRVLMRIDPDNINOCHOIAVCLREHLKGMLNALVEARVRVOESKLLCMF - -PASKRLLSDQEKRIAVM 1183 TECCAKYEPYRAFQTITAKSMNKKVLLRVDPENINICHSVASALLKQQNDVLSSLLNMQTACRDSKLLSCF - -RQTRRFMSDHQNRIEAT 1187 AEAAASYKPSMLTRWAKPAKEVSNVILHVNQKNVCEAIGVVRSLIASTKSLIQSKKHNQNLHRESPLACLFTKRTTLELESKLGEQIKLG 124 AEAVSSYKPSMITQWAKPAKEVANVILHVNNQNVHEAINVVRSLIVSTQAQILSKRHAQNLHRESPLACFFAKSTTMELEARLGEQIKLG 1242 AKAAQAYRSTVKSRWGKPVKEAANVIMHANQSNIHDAIRVAQSLRNEAQRQIQEKERVQNLHRESPLACLFSKDTVRGLDXKIGEQIQMA 1233 TKALAAYQSTVKERWGKPIKEAMNVIMHVNQENIYETLAVARVMRSEAVKSMQQRQNT IKLHRNSPLSCLFGKKTI QQLEEKLGQQVRLA 1233 VKAVANYKPNMLTVFGOPKPRNIGLIMRVDETNVFNTMRMARLLKSDYEOOILNKKAALOAOKESPMAYFLSTRVVDSLASKLSOOISOA 1242 $\begin{array}{lll}\text { VKAVANYKPNMLTVFGQ KPRNIGLIMRVDETNVFNTMRMARLLKSDYEQQILNKKAALQAQKESPMAYFLSTRVVDSLASKLSQQISQA } & 1242 \\ \text { AKAVAHYKPNMMTVFGSKPAKGVSLVMKVDETNVFDTLRVARLLKRDYENOISSKKTAINTORESPISYLLSTRIVDDLTAKLTOQIORA } & 1242\end{array}$ $\begin{array}{lll}\text { AKAVAHYKPNMMTVFGSKPAKGVSLVMKVDETNVFDTLRVARLLKRDYENQISSKKTAINTQRESPISYLLSTRIVDDLTAKLTQQIQRA } & 1242 \\ \text { LRCADLYKPSVLTRWGRPVKQSTNVLMHVNSNNVHETIRVATLLRHDYSQQIHMKQHAQQLHQNSPFAYFF SKKTVDELSTNIGKQIAIA } & 1245\end{array}$ ANCVEKYRPNVLTRWGRPVEQTTNVLMHVNQENIHATIRIANLLRYDYQQQIQQKKQAQQLHKDSPFAYFFSSKVVDELASNIGKQVAMA 124 TNCVEKYRPSVLTRWGRPVEQTTNVLMHVNQENIHSTIRIVNLLRFDYQQQILQKKQAQQLHKDSPFAYFFSTKVVNELENNIGKQIAMA 1244

Striga-associated poty-like virus 1 Bellflower veinal mottle virus (YP_009508455.1) Artichoke latent virus (YP_009129267.1) Narcissus latent virus (QDC21212.1) Broad-leafed dock virus A (YP_009507671.1) Crow-dipper mosaic virus (QGV12925.1) Alpinia oxyphylla mosaic virus (AW077093.1) Cardamom mosaic virus (YP_009508901.1) Yam chlorotic necrosis virus (AZQ00683.1) Chinese yam necrotic mosaic virus (YP_006590058.1) Yam chlorotic necrotic mosaic virus (YP_009507672.1)

Striga-associated poty-like virus 1 Bellflower veinal mottle virus (YP_009508455.1) Artichoke latent virus (YP_009129267.1) Narcissus latent virus (QDC21212.1) Broad-leafed dock virus A (YP_009507671.1) Crow-dipper mosaic virus (QGV12925.1) Alpinia oxyphylla mosaic virus (AW077093.1) Cardamom mosaic virus (YP_009508901.1) Yam chlorotic necrosis virus (AZQ00683.1) Chinese yam necrotic mosaic virus (YP 006590058.1) Yam chlorotic necrotic mosaic virus (YP_009507672.1)

Striga-associated poty-like virus 1 Bellflower veinal mottle virus (YP_009508455.1) Artichoke latent virus (YP_009129267.1) Narcissus latent virus (QDC21212.1) Broad-leafed dock virus A (YP_009507671.1) Crow-dipper mosaic virus (QGV12925.1) Alpinia oxyphylla mosaic virus (AWO77093.1) Cardamom mosaic virus (YP_009508901.1) Yam chlorotic necrosis virus (AZQ00683.1) Chinese yam necrotic mosaic virus (YP 006590058.1) Yam chlorotic necrotic mosaic virus (YP_009507672.1)

$$
\begin{aligned}
:::: *^{*}: \quad: \quad & : \\
& \\
& \text { CI } \mid 6 K 2
\end{aligned}
$$

KRNIOEVDKHIGKLTMYDTFVRDCNVPESFDMAEFQKVHQHMELQ|ARGNNNETELKKVLDMKHSDELKVRDVLVHHSGKIALGMVAMSG 1272 KRNVSKIRDHLAKLERYDTFVRDKEINGEFSHADFGSVFDHMSLQ|MRGEANNNEVRKILQLEDNAQVNVSDLFIHNGDKIAIGLLATTG 127 ERNLVKLTKLLGNLELFMNLDEMKDEEPELSSGDMEEIGRVLELQ|MQTTCNEDHIATVLHLEELPSTTFREAIVIGRKRVACALVLMCI 1332 ERNLSKLKKFASNLELFANINVMQDTELELTSSDMEE IGKVLELQ|QETTCNEGHVQKVLHLEDMPSTSFREAIVVGRKRVAVALTLMCI 1331 RRNIEKLDKFISTLEIFAASOEVGGE -MEITSEDLSDIGRCMELO|MDTTCSNEHIOEVLGLEELPSVTFKDAIILGRORVATAMMILCV 1321 ORNLTKIDKFIGSLEMFATVNEHTDEGFEVTPEEMDNIGACMELO|MNTTCNEEILOKVLKLEELPSVSFRDAIIVGREKVMVATMILCV 1322 ERNIVKLTTFITNLEIFMNTANSNVE - QDMQTDDLEE IGRSMQLQ|MDGNLTRHALTNILKLEDIPNVSFREAILIGNKRSLIALSFLVC 1330 ERNIRKLDGFITNLEVYANAPLPNEP-AVMGHGDYEE IGRCMQLQ|MEGKLTRESMIESLQLEDIPNASLKDAILLGNRRSILALSFLAC 1330 QRNIQKLDRFISNLEIFVTMNEVDGD - IELTQQDMHEIGQSLDLQ|ADGKFSRDTLCDTLNLESLPSTTFRDAVVIGRKKAIWAIMILCC 133 QRNVSKLDKFISRLEMFATMNEMAGD-VEVTQQEMHEIGQCLDLQ|AEGTFSKDNMNVILSLETLPQTTFRDAIIIGRKKAIWGIMILCC 1332 QRNVAKLDKFISRLEMFATMNEMADD -VEVTQQEMHEIGQCIDLQ|AEGSFNKENVNVILNLERLPQTTFRDAIVIGRKKAIWAVMILCC 1332 **: : :

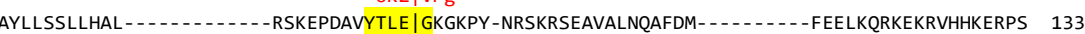
--RTTETITASSLE | GKGKPIRNRDKRSEARAVNESFNFIE-RMRAESETQTVKKRRDKGK ---QQSD 1348 AAFGGLAWYYLWDDDTGLDNKWNKKNKKAVLKDVLE |MKGKSF-NRDKRSA- - TAYEKILKDSYEGEDNYNLDEFRTRRKGRA--DADKT 1416 AAFGGLWYYLWDDTGLDNWWKNKKAVLKDVLEMKGKSF-NRKSA - TAYEKILKDSYEGEDHNEFRTRKKGRA- DADKT 1416 作 AAFSGLAWWLMWDEDGGLDNEYNKEQHESVYTKVLE | MKGKAF-NRDKRSE --ASLLAYEKADVYGENLQDVQMFKSKRGKSKKMHDDSK 1408 SAFAGLAWYLTWDFDEGLENSYNKRQRVAVHNKVLE |MKGKGL-NRDKRNV--AMQETYDEAYTSIRDDEDFDRVRSRRQRAK --ETDIA 1414 GAFAGLAWYLTWDDNEGLNNKWNKKORVAVHKEVLE |MKGKHL -NRDKRNV - -ALODTFDEAYTAIRGDEDFFERVRSRRKGAK - -EKDIA 141 AAFGGLVWWLMWDDDDGLNNEENKQRRKAVCDEVLE |MKGKSF-NRDRRNP - -MMQDT IDMADFYMRDNEDFVKLKKKKNNNARDDSHKG 1419 AAFGGLAWWL LWDDDEGLNNDENKDRRNEVCSKVLE|MKGKSF -NRDRRNP - -MMODHFDAADFYMRDVEDFASLRSRRKVSR -VDDAVS 1417 AAFAGLAWWLLWDDDEGLNNTENKERRDEICNHVLE | MKGKAF -NRDRRNP - -AMODHFDTADFYMRDDEDFOTLRSRRKTSSGPNDAIS 1418

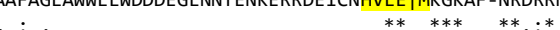

VVSNLLKKTNP-FVNFYDIADDSAVTEAVFKMLDGSVVHKTTTPIADIPNLGRIIAEREMDDSQPVLSWADEAERVDPDQLICEVTLKDG 142 AVSRLLTKTNP -FVNFYDIA-DADVETAIFSTLKGKVIHETATPVSDVKRL -DLISTNVDGDGEPIN-LSDE - - - - - DDLMCYITLKDG 142 PFENLMTKAAP-FITMYDITSDENVVNAVFMDHNKOAFYETADPLKNMGEVKKHLEOMKLKOPV-FK-WGDEAD-- - -DDVFCDVTTRDG 149 VFENLMTKKGP -FVTMYDVTSDENVVNAVFLDTNKOAFYETGNPLANMKNVRSHLEDHLHNKST -GL-WSEIDD - - - DEE IFCDVTKKDG 1498 PLDRFMSKGPMVFKNFYDIASDEEVAKAIFSDENNHVFYETANPL KHMKEVEKHLNAHKATSNL - LA-WGDEAN - - - DL IYCTVTKNDG 1498 PLNKFLNAEPP - FISLYDITTDDNIVSAVFQDTNRQAFYETANPLAHMKEVEEHLQKHIEKGEL - IQ-WADAAD- - - -DTVYCVITKNDG 1491 PVMRHMRSEKP-FITLYDLTLDSDITHAVFSDHNSQAFYETANPLANLDKVKQHLEEHRQGEKI -IF-WSDMTD - - - -DTIFMTITKKDG 1497 PVMRYAQQKRP-FLTLYDLTLDEDITHAVFADHNNQAFYETANPLANLKDVETHLQSHKDKGGV-VF-WSDYAD- - - - DTIFMTITKRDG 1497 LVQRMMSQSKP - FITLYDINNDADIVNAVFMDHNKQAFYETANPLKNMEQVRQHLDDHKAKEGGQIF - WGDDAD - - -YTLFCNITKRDG 1503 PVLRYAAKSRP-FITLYDINVDSEVATAVFODHNGQAFYETANPLKNMDLVREHLNKHKAKDGTOIF -WSDESD - - - FDIFCKITKTDG 1501 PAMRYAMKSRP - FITLYDINVDSEVASAEFODHNGQAFYETANPLKNMNLVRKHLEEHKQKNGTQLF-WSDESD---- FDIFCKITKTDG 1502
Striga-associated poty-like virus 1 Bellflower veinal mottle virus (YP_009508455.1) Artichoke latent virus (YP_009129267.1) Narcissus latent virus (ODC21212.1) Broad-leafed dock virus A (YP_009507671.1) Crow-dipper mosaic virus (QGV12925.1) Alpinia oxyphylla mosaic virus (AW077093.1) Cardamom mosaic virus (YP 009508901.1) Yam chlorotic necrosis virus (AZ000683.1) Chinese yam necrotic mosaic virus (YP 006590058.1) Yam chlorotic necrotic mosaic virus (YP 009507672.1)

Striga-associated poty-like virus 1 Bellflower veinal mottle virus (YP_009508455.1) Artichoke latent virus (YP 009129267.1) Narcissus latent virus (QDC21212.1) Broad-leafed dock virus A (YP_009507671.1) Crow-dipper mosaic virus (QGV12925.1) Alpinia oxyphylla mosaic virus (AW077093.1) Cardamom mosaic virus (YP_009508901.1) Yam chlorotic necrosis virus (AZ000683.1) Chinese yam necrotic mosaic virus (YP_006590058.1) Yam chlorotic necrotic mosaic virus (YP_009507672.1)

Striga-associated poty-like virus 1 Bellflower veinal mottle virus (YP 009508455.1) Artichoke latent virus (YP 009129267.1 ) Narcissus latent virus (QDC21212.1) Broad-leafed dock virus A (YP_009507671.1) Crow-dipper mosaic virus (QGV12925.1) Alpinia oxyphylla mosaic virus (AW077093.1) Cardamom mosaic virus (YP_009508901.1) Yam chlorotic necrosis virus (Az000683.1) Chinese yam necrotic mosaic virus (YP_006590058.1) Yam chlorotic necrotic mosaic virus (YP_009507672.1)

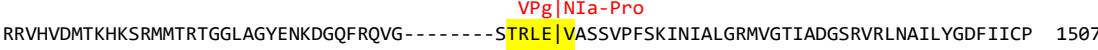
RDVMVRLDRHRSRQLTRTGGLMGYPNRDGEFRQVG - - - - - - - TTKIE |MKGPIPFTNISTKCVNMVGLIYANGRPVMNCVLYGDF IVCP 1509 TTIRVRLTPHSSORLTSTHGVOGYAODEGRYROTGDAEVLKMPTOHLE |VDTRLADNMVNLDVGNMIGLVSVKGG-NANCLLYKDWVIMP 1587 MVIRIRLTPHKSMRLTSTSGROGYSEHDGDFROTGDAEILKOPDQILE |VDTRLSNNHVSVEAGAMIGITTLOAG-SMNCILYKDWIILP 1586 $\begin{array}{llll}\text { MVIRIRLTPHSMRT } & \\ \text { SVYRVRLTPHNPRLTKHHGVQGFENKFGIFRQSGQTEVLQRPQQELE | IATHLQTSQVNLDVAKMIGTVTVDGG-LICCILYKDFLVMP } & 1578\end{array}$ TVMRVKLTPHQPNRVTNTFGTMGYHNKAGQYRQTGPTEILKHPPHSLE | IATHLQTNQINLDVGSMIGIAEAGGG-QINCILYKDFIILP 1579 SQQRVKLTPHASQRKTKTGGVQGYASHEGEYRQTGDVEILKQPTQVLE | IGTQLTNNQANLDILNMIGHVNIETG-RLHCILYKDFIIMP 1585 TVQKVRLTPHSSERTTRHGGQQGFEHEGQYRQTGDVEILKQPQQTLE | IDTRLSNNNTNLE IMNMIGHIQIGEG-RLHCLLYKDFIIMP 1585 SVLRVKLTPHIPSKSTTSGGAOGFONKADCYROTGETEVLVOPTQALE | IDTRLPVNNINLDVANMIGKVRMANG-TLHCILYKEFVILP 1591 TIMKVKLTPHEPLRMARR -GTOGFVEKEDCYRQTGQAEILOHPGVNLE |MATRLPENKLNLOVADMIGKVSMSEG-TIHCILYKDFILMP 1588 TIMKVKLTPHEPLRMARR -GTQGFVEKEDCYRQTGQAEILQHPGVNLE |MATRLPENKLNLQVADMIGKVSMSEG-TIHCILYKDFILMP
TVMKVKLTPHEPTKRSKH-GTQGFSNMEDCYRQTGQAEILHHPTQALE |MATRLPDNKTNLQIADMVGRVTMSEG-TIHCILYKDFIIMP
1589

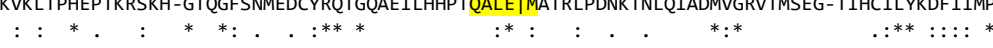

AHTQVLSLPITFRFEHATCTVDHV-EAMKFEKCDLILIKRPNSIAPVKVVSKATTITEPTLIQIIYRDLGSFSCHVSASDLAVPFDNGRF 1596 AHIKLVGPELKFRFQHATCTF -VVDEYMAFTQCDLILIKRPREIAPVAVIAKCGVLTEPSYVQLAYRNQQNLDGTLSASDICTPFDNGRW 1598 AHIMMRPLPLTFAFKHYTCTISELPECYSFIGYDLLVIRRPRNLAPVR AHVMMKKLPMRISFSHCTVVVTELPEMYSFIGYDLVLVRRPSELAPIKCQAHCGTAHDGMLVQMIYKKPVTNKVVPTITAPIHQTKEHRW 1668 AHVMLKSLPIKFTFKHAHVIVSELPQAYSFPGFDIIVVKRPTTLPPVKCVAYCGIAHENMVVQMLYKKLVSHKLVTTITAPIHQTKEHRW 1669 AHVMQKELPITLSFKHYTVKVEELGEVYAFVGFDLILMKRPHQLAPVKCVASISQAQEAMIVQMVHKKFVTLKPVITITAAIHQTKEMRW 1675 AHVMQKPLPLTISFKHYTVKIPELQEAYAFEGFDLLCIKRPPQLAPIKCSASLATAQEGMIVOMLHKKFLTNKPIITVTAPIHETSELRW 1675 AHAMMSKLPIDLVFKHKTITISEFPEAYCFPGFDIMLTKRPTSLAPVACRATVAQASDGMTVQTVHKKHVTEKTVLTVTAPTHORDDFW 1681 AHAMIKQLPMEISFKHFTITIDTLPEAYCFPGFDIVLIKRPAKLAPVRCHATLAQATDGMIVOMVHKKSVSDKTVLTITAPIHORDDWRW 1678 AHAMITKLPMEITFKHYTIKIGTLPEAYCFPGFDVMLIKRPTNLAPTRCHATLATATDGMIVQMLHKKSVSDKTTLTITAPIHQRPDWRW 1679

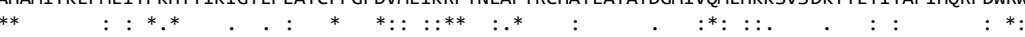

NIa-Pro|NIb

SYSVSTKDGMCGAAIVDVKTGMITGIHVSANDLIKRNFMEPFSTSMVDVLQKKAPFVRDE - - . - - - -VWYFDSIASGYAPHELDRLQ|S- 1677 TYTISTKKGMCGAAVIELKTGKFVGIHVSANEVIRRNFMEPISESMVOVLOKKEDFIPSR - . . . . - DWTFTSTECGYMPGEISGLO|AN 1680 EHOIPTIYGMCGAPMLDVSSGKIVGIHILGDTARKCNTFEGFPPDMLKLVNSNDPKVRNLFVRERVKTWEFVPEMHGHNSARIKNLQ|I- 1765 $\begin{array}{lll}\text { EHQIPTIYGMCGAPMLDVSGKIVGIHILGDTARKCNTFEGPPDMLKLVNSNDPKVRNLFVRERVKTWEFVEMHGHNSARIKNLQ| I- } & 1765 \\ \text { EHQIPTAAGMCGSPVFDVASGKIVGIHILGDIMRKRNTFEAFPGDMMKLVNSNDPKIKDLYIKNRLREWNFEAEVHGHDSRRLINLQ|G- } & 1764\end{array}$ AHQIPTHNGMCGCPVLDVVTGKIVGIHVMGDLAKKHNVFEAFPSEAITIMGTNDRKVHASYFRNKVNMWVFQPEMHGYLAKNLVNLQ|M- 1756 AHQIPTENGMCGCPVLDVATGKIVGIHVMGDHRMKHNVFETLPPEVLTLIQTNDKKVHQTFHRNQLKAWVFQPEMHGYLSKNLTNLQ|MN 1758 AHQIPTIVGMCGAPVLDTOTGKIVGIHVMGDTLKKHNVFETFPSEALEILGTNDKKVHORYFNNRLKAWKFOPEVHGYDPRKIOGLO|N- 1763 AHQIPTWGMCGAPVDTOTGKIVGIHVMGDSFKKHIVFETFPSDALEILNTNDKKIHORYISOKIKTWTFIPETHGYDPRKIOGLQIM 1763 AHQIPTVAGMCGAPVLEVATGKTVGIHVMGDTFMKHVFFTFP AHQIPTVSGMCGAPVIDVASGKIVGIHVLADSLKMHNVFETFPSQLLEIINTNDKKVHQRYHQARVNDWTFLPEAHGYFPSELVGLQ|M- 1766 AHQIPTVSGMCGAPVIDVASGKIVGIHVMADSLKMHNVFETFSPDMMEILNTNDKKVHAKFHQARLMDWVFLPEAHGYEPSKIKGLQ|M- 1767 
Striga-associated poty-like virus 1 Bellflower veinal mottle virus (YP_009508455.1) Artichoke latent virus (YP_009129267.1) Narcissus latent virus (QDC21212.1) Broad-leafed dock virus A (YP_009507671.1) Crow-dipper mosaic virus (QGV12925.1) Alpinia oxyphylla mosaic virus (AW077093.1) Cardamom mosaic virus (YP_009508901.1) Yam chlorotic necrosis virus (AZQ00683.1) Chinese yam necrotic mosaic virus (YP_006590058.1) Yam chlorotic necrotic mosaic virus (YP 009507672.1)

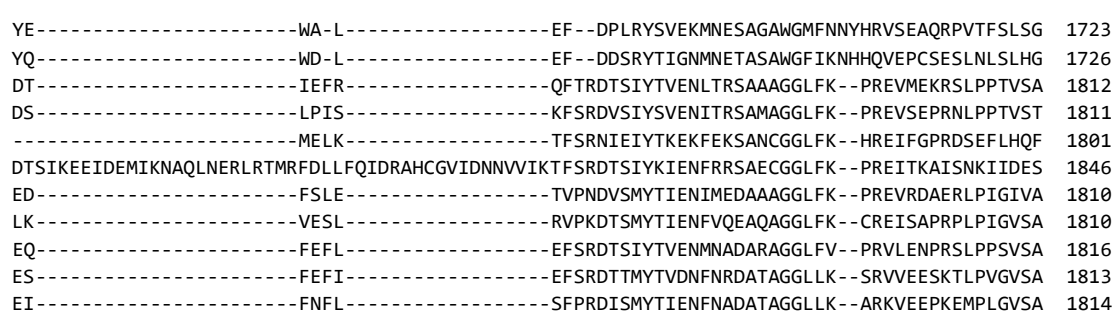

GGFEILGEATSNLCNKHKIVGESVYWKEFKQCCPDLVEGIEEYEDAYCPSALNREAYYKDVGKYDR - -HLRCRADINLLIKARNMVKDDL 1811 -GFEMLGKSVSHLCSKHKIVGLSPYWQEFKQLCPDLVEGIEELEDQYAPSALNRDAYYKDISKYNR --DLACKCDIQRLEKAREMVAHDL 1813 IHMHNLAYSNGLLNTRHIFEGENPYWKQFKLCNEWVDPIVERYEDNYMPSALNREAYWKDLLKYNR - PQHLCKVDDVALKSSVAQLVREL 1901 LHMTNVAYANGLLNTRHIFEGENPYWKOFKLCNPHLTDAVSEYEDKYLPSALNREAYWKDLLKYNR -PLHQIKPNEAALHASMVKLIRVL 1900 EHFDNLAYAHALLNTRHTYVGESPYWLEFKRNHOSLVRGIEEYEDAYLPSRLTHTAYWKDL SKYNR -AYKGVDHDEKILLSAADCL IHML 1890 EHMDNMAYSHAILNTKHVYVGENPYWIQFKANHKQLVQGIEKFEDNYLPSELTYNAYWKDLLKYNR -PLKSSKHDEKALLMAIKKVVTVL 1935 QDMTNLAFANALLNKRHVYIGESPYWTEFKRRHAQHVKGIHEFEDEYAPSILSYDAYWKDLLKFNRQSNATPQFDKRILNLAAQAVIRNL 1900 QHMQNVAFANAILNKRHTYVGESPYWREFKRIHSEHVRGISAFEDFYAPSALTFDAYWKDLLKFNRTSASDPTWNEKALKHSMLATIQAL 1900 LHMDNLAYMNGLLNPRHVITGESPYWLEFKRFHPRQVRGIEEFENKYAPSVLNYDAYWKDLLKFNRLENANLQYDKEILKCAALAVVNQL 1906 THMSNVAYMNGLLNPRHTITGESPFWREFKRCHPKQTKGIEEFENAYAPSVLSYDAYWKDLLKFNRAEFKADKIDKDILKCATLALVKQL 1903 $\begin{array}{ll}\text { THMSNVAYMNGLLNPRHTITGESPFWREFKRCHPKQTKGIEEFENAYAPSVLSYDAYWKDLLKFNRAEFKADKIDKDILKCATLALVKQL } & 1903 \\ \text { INMKNVAYMNGLLNPKHTVTGESPYWKEFKRCHPRQVKGIEEFEDAYAPSVLSYDAYWKDLLKFNRVEHSKSGLNEEILRHATLCLVRQL } & 1904\end{array}$

KKAGLFATRLMTAAEVLGDLDVNTAAGALYACKKKLLFTGMTDDQVVQLANCCYDKLVKGESVGIWNGSLKDELRPVEKVLENKTRVFTA 1901 KVAGMRPTRVMDAEEVLGDLDVSTAAGALYACKKKVVFAGWDDEMLINFATLCKSKLISGENVGVWNGSLKDELRPIEKVVANKTRVFTA 1903 ERAGMTKTKIRTTDQVLEDIQWGKAAGPLYGMKKKELCKNLTMEELTSLALHCRSELNKGKNAGLWNGSLKAELRPKIKVEANKTRVFTA 1991 RESGMTSTRIRTCNEVLEDIQWNKAAGPLYGMKKEELCKNMTMEDLTALAIHCRTELRRGKNAGVWNGSLKAELRPKEKVELNKTRVFTA 1990 ESAGMTPTRIRTPEEVLSDIQWNKAAGPMYGMKKRELCQHLTEEELIAMAIHCRRELVRGENAGIWNGSLKAELRPLEKVEQDKTRVFTA 1980 EQAGMRKTRIKTPIEVLSDVQWNKAAGPMYGVKKRELCMNMTEEELITMVIHSRNELVKGQNAGIWNGSLKAELRPIEKVNQHKTRVFTA 2025 QQAGLTATKIRTTNOVLDDVOWTTAAGPLYAMKKKELCKDLTEEEELOSLAIHVRORLIAGKNCGVWNGSMKAELRSIEKVOOAKTRVFTA 1990 KDAGMVPTRVRTTFEVLSDIQWSTAAGPLYAMKKKELCKDLSTEELDALAIHVKTRLIKGENCGVWNGSMKAELRPIEKVQANKTRVFTA 1990 KRAGMTETRIRTSEEVLGDLQWGKAAGPMYAMKKNELCKNLTDEELTTLTIHCKKQLIEGRNCGVWNGSLKAELRTKEKVSQNKTRVFTA 1996 KDSGMQQTKIRTVEEVLDDVQWGKAAGPMYAMKKLELCKDLSEEDLTALAIHCRTQLLKGKNCGIWNGSMKAELRVVEKVLQKKTRVFTA 1993 KEAGFKPTRIRTVEEVLSDVQWGKAAGPMYAMKKLELCKDLTEEELVSLAIRCRTQLKRGHNCGVWNGSMKAELRTIEKVLQKKTRVFTA 1994

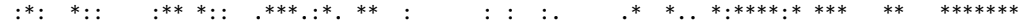

APLTTLIGGKFVVDDFNKQFYGTHLNARHTVGINPWAGGWHRLAQFLGGQDMPYYVSGDGSRFDSSLDPILFDQVLKLRLELM--PDVNG 1989 APITTLVGAKFFVDDFNKQFYTTHLKARHTVGINPWEGGWNRLADFLGGSQMPLYVSGDGSRFDSSIDPLLFDQVLKLRLQFS --DQSDD 1991 APITTLIGSKFFVDDFNKQFYASHLKAPHTVGINKFSNGWAKVHDKLNREGW-LHGSGDGSRFDSSIDPFLFDMIYTIRCHFMCDDDRRE 2080 APITTLIGAKFYVDDFNKOFYATHLKAPHTVGINKFONGWARVHDKLNHPGW - LHGSGDGSRFDSSIDPFLFDIIYTIRCHFMRDEDRGE 2079 APITTLVGAKAYVDDFNKOFYATHLHAPHTVGINKFQRGWERVHRYLDEPGW-LHGSGDGSRFDASIDPFLFDVIYSIRCHFMAPECKEE 2069 APITTLLGSKCFVDDSNKQFYNTHLKAPHTVGINKFQKGWERVHDYLNTPGW - LHGSGDGSRFDASIDPFLFDAIYSIRLHFMDERDQGE 2114 APITTLIASKFFVDDFNKQFYETHLKANHTVGINKFSRGWERLYNFLDRPGW-KHGSGDGSRFDSSIDAFWFDYLLTIRLSFFTNDERAI 2079 APLTTLIASKFFVDDFNKQFYATHLKAPHTVGINKFARGWEQLYTYLHKDGW-LHGSGDGSRFDSSIDDFWFDKLYTIRAHFFHEDDKSV 2079 APITTLVAAKHFVDDFNKQFYSTHLKANHTVGINKFQRGWEDLYKFLDRPGW-LHGSGDGTRFDSSLDPFWFDLLYSIRYHFFTHDDQEV 2085 APITTLIGSKFFVDDFNKOFYGTHLKASHTVGINKFORGWEKLYNFLNVDGW-LHGSGDGTRFDSSLDPFWFDILYSIRSNFFCEEDROD 2082 APITTLIGSKFYVDDFNKQFYGTHLKANHTVGINKFQRGWEKLYTFLNKDGW-LHGSGDGTRFDSSLDQFWFDLLYSIRVETFADEDKDE 2083

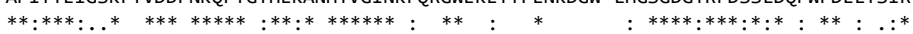

SHAALKNLYHEIVFTPILLENGQIVMKKVGNNSGQPSTVVDNTIILMMCFYYACLRKTNDE - -DWIRSNFLFVCNGDDQKCAMTQDFLDK IKQALKHYHETVYTPILLENGHTVMKKVGNSGQPSTVVDNTLVLMMCFYCALAVSDDP - SWIRNNFLFVCNGDQKCAMTQEFIDA ATRAMSNMFREFVFTPIHTISGNILVKNVGNNSGQPSTVVDNTLVLMLSFYYAYAVKTKDYAFDHIDDRFVFVCNGDDNKFAVSPAFVKE 2170 ASMAMSHMFREFVFTP IHTINGNILIKRVGNNSGQPSTVVDNTLVLMLSFYYAYARKTNDLTFDRIDEDFCFVCNGDDNKFSLSPDFVAK 2169 AEAALSHMYREFVFTPVHTIAGNIIMKRLGNNSGQPSTVVDNTLVLILSFLYAYISKTGDTTCSQLHERMRFVCNGDDNKFSISREFEHE 2159 AEQALSHMYREFVFTPIHTVTGNIIMKKLGNNSGQPSTVVDNTLVLMLSFYYAYIRKTGDFECEEIENRFKFVCNGDDNKFSISPEFAOM 2204 ATOALKNMYRFFYTPIHTVSGIIVKQVGNISGQPSTVVDNTLILMMSFFYAYICKTGDDNCEFINERFRFVCNGDDNKFSSPQFASE 2169 AQOALGNMYREFLYTPIHTTSGNILVKOVGNNSGOPSTVVDNTLILMMSFYYAYIMKTODFNCECLNDCMRFVCNGDDNKFSLAPDFVKK 2169 $\begin{array}{ll}\text { AQQALGNMYREFLYTPIHTTSGNILVQVGNNSGQPSTVVDNTLILMMSFYYAYIMKTQDFNCECLNDCMRFVCNGDDNKFSLAPDFVKK } & 2169 \\ \text { AKDALSHMYREFVFTPIHTTTGQVLMKKVGNNSGQPSTVVDNTLILMMAFTYAYIKKTDDRTCERMDECFRFVCNGDDNKYSISKEFNEK } & 2175\end{array}$ AKTAMAHMYREFVYTPIHTITGQVLVKKLGNNSGQPSTVVDNTLILMLSFLYAYIRKTNDRTCAQINQRFKFVCNGDDNKYSVSPEFHEE 2172 ARVALGHMYREFVFTPIHTITGOVLVKTLGNNSGQPSTVVDNTLILMLSFLYAYIRKTGDTTCOHIDSRFKFVCNGDDNKYSVSODFHAT 2173

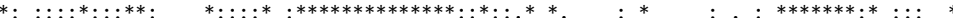

GCFDFDRMLSECGLTYEFDELTSDIKEYPYMSLTMVESETGHIGFMLDQRRIVAINQWMTKKGVLGVAQRAFPAMLHAYNDPWLFTIMHA 2167 GGLNFENQLRQCGLNYEFDEPTTNIAEYPYMSLTMVPQGNGVFGFILNPERIVAINQWMPKKGILGVAQRAFAAMLHSYNDKWLFAIMHS 2169 FGGVFTNEIAQLGLNYEFDALTPDITANPYMSLTMISVCGR-IGFQLNPERILGIVQWIKKGGVVHASQAAFAAMIESFNDPDLFSVMHS 2259 HGGSFENEINELGLTYEFDDLTPDIMKNPYMSLTIVOVGER -IGFOLNPERIVGIVOWIKKGGVLHAAOAAFAAMVEAFNDPSLLFTVMHS 2258 FGGDFSNEIGELGLSYEFDILTDNIMENPYMSLTMVOHPSG -VGFOLNPRRIVGIVOWIKKGGVVHAAOAAFAATIEAYNDPWLFGIMNL 2248 FGGDFSQEITELGLKYEFDELTKDITENPYMSLTMIRTKSG - IGFQLNPERIVAIVQWAKKGGLIHAAQSAFAALVESYNGPWLFSIMNL 2293 FGTDFSGEIKQLGLNYIFDAITDDITENPYMSLTMVRTHEG-IGFTLHPSRIIAITQWMKKGNLIQATQAAFAAMVEAYNDPWLFGILHL 2258 YGGEFTTEIKQLGLTYEFDDLTEDITENPYMSLTMVRTCSG-IGFSLHPSRVVAIVQWIKKGDIIQATQAAFAAMVEAYNDPWLLFSILHL 2258 YSGDFSKEIGELELVYEFDDLTDDITLNPYMSLVMVRTKQG-IGFQLHPERIVAIVQWIKRGDILQATQAALAATIEAFNDPWLFFIMHL 2264 FSGDFSREIAELGLTYEFDDLTADITONPYMSLVMVRTPGG-IGFQLNPERIIAIVQWIKRGDVLQASQAAFAAMIEAFNDPWLFGVLHL 2261 $\begin{array}{ll}\text { FSGDFSREIAELGLTYEFDDLTADITQNPYMSLVMVRTPGG-IGFQLNPERIIAIVQWIKRGDVLQASQAAFAAMIEAFNDPWLFGVLHL } & 2261 \\ \text { FGGDFSKEIAELGLTYEFDDLTEDITLNPYMSLVMMRTPGG-IGFQLNPARIVSIVQWIKRGDVLQAAQAAFAMIESFNDPWLFGILHL } & 2262\end{array}$

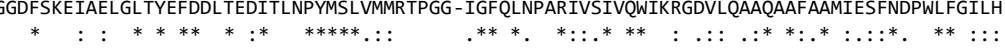

CIb|CP

YLVWLLVNYEDEILYQMRQTGERVSYLSPAYVKMLHYGG YLYWLLLSYEQELLWAIEQTGESVSYIPPYAVHVMHYGG $\ldots$ YLIWLLVTYRQELRYAMHNDLVSVYYMDPAQVFALHYNDATD - - - - HHTWFSDDLDEPSSDDDDDDVQTQELQ|MNR YLVWLLVTYKDVLLYAQENDLGSVCYMDPCQVFALHYGSSEG - - - - - - - - - - LESVDFESDNESANDADDDVTPSLELQ|MDV - YLIWLLCEYKDALVYANEHELATICYMDPLOIHALHYEVHSE YMVWLLSEYKDAFIYAEENGIATICYMDPCOIHALHYARAEDSGTPYYAILDRAEYIKEPNEATYEOOOLOMKSDE AFOTLO|MDFNKKE YLVWLIIEFRDELEFAKDNDVLGVTYMDPCQVHALHYGINEA- - . - . - - - - - QIQEEDEDWTDDEDENLISQTQHFQ|MDL YLVWLIIEYKDALNFARVNGIFGVYYMDPCQVHALHYGIPTA - - - - - - - NELKEDEDYDDDSDEDLEIVEFCSQQFQ|MDL YLVWLICENSELLAFACRQEMQSICYMDAYQIYSLHYDKQDD - - - - - - SLKPLLDEAIEENRYMNGKGYVSFDEAEGSQVLE |MDL YFVWLLCQYREEIRYAMDHDLGAVCYMDAYQVYALHYDTRDD - . - . - . - . - INDLQIDSASCEIEKTVVVAGSTQHISLQ|MDL - -

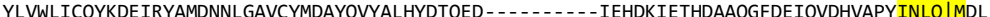
$*^{*}: *^{*}: \quad::: \quad: \quad: *^{*}: \quad::^{* *} \quad:::$ :
2213 2215 2331 2330 2300 2382 2328 2331 2343 2335 2337 
Striga-associated poty-like virus 1 Bellflower veinal mottle virus (YP_009508455.1) Artichoke latent virus (YP 009129267.1) Narcissus latent virus (QDC21212.1) Broad-leafed dock virus A (YP_009507671.1) Crow-dipper mosaic virus (QGV12925.1) Alpinia oxyphylla mosaic virus (AW077093.1) Cardamom mosaic virus (YP 009508901.1 ) Yam chlorotic necrosis virus (AZQ00683.1) Chinese yam necrotic mosaic virus (YP_006590058.1) Yam chlorotic necrotic mosaic virus (YP_009507672.1)

Striga-associated poty-like virus 1 Bellflower veinal mottle virus (YP_009508455.1) Artichoke latent virus (YP_009129267.1) Narcissus latent virus (QDC21212.1) Broad-leafed dock virus A (YP_009507671.1) Crow-dipper mosaic virus (QGV12925.1) Alpinia oxyphylla mosaic virus (AW077093.1) Cardamom mosaic virus (YP_009508901.1) Yam chlorotic necrosis virus (AZ000683.1) Chinese yam necrotic mosaic virus (YP_006590058.1) Yam chlorotic necrotic mosaic virus (YP_009507672.1)

Striga-associated poty-like virus 1 Bellflower veinal mottle virus (YP_009508455.1) Artichoke latent virus (YP_009129267.1) Narcissus latent virus (QDC21212.1)

Broad-leafed dock virus A (YP_009507671.1) Crow-dipper mosaic virus (QGV12925.1) Alpinia oxyphylla mosaic virus (AW077093.1) Cardamom mosaic virus (YP_009508901.1) Yam chlorotic necrosis virus (AZQ00683.1) Chinese yam necrotic mosaic virus (YP 006590058.1) Yam chlorotic necrotic mosaic virus (YP 009507672.1)

Striga-associated poty-like virus 1 Bellflower veinal mottle virus (YP 009508455.1) Artichoke latent virus (YP_009129267.1) Narcissus latent virus (QDC21212.1) Broad-leafed dock virus A (YP_009507671.1) Crow-dipper mosaic virus (QGV12925.1) Alpinia oxyphylla mosaic virus (AW077093.1) Cardamom mosaic virus (YP_009508901.1) Yam chlorotic necrosis virus (AZQ00683.1) Chinese yam necrotic mosaic virus (YP 006590058.1) Yam chlorotic necrotic mosaic virus (YP_009507672.1)
- DDEGKAKDTNNKKDTG- - - - - - KGIEGSGTQAELLG--GIQT-_. -EEIEAAARKEQEEKDAAAKEESERKEAEEARGIRERTRKGKDEIPG --PTATPSSSDSSLE-KGNENISEPQGDPEEKEEDVKWVMPAL 2417

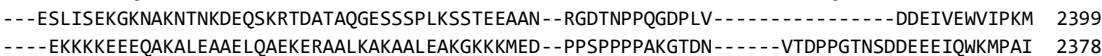

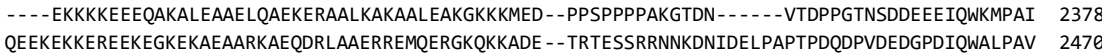
- - - - - - - TAPTQRTPLVPTTSTP - - - -AVTPPNNQQLVPSTPMDGA- -STSQQQPLNQNRE - -VIEQPPQATPDSNNDENE IEWRIPPI 2402 - . - - VGTPTAPROGSTIASASTSGTASTNLPGSGGTRTAPLAPITGQOHAENPPOPVESFDA - . - - -QQQDFAPSGGDDDTDIQWRIPPT 2412 _. - - TLAPTEOTTOKDKGKOHEOR - . . . . - REGRPGPSTOPIETG - DNNNNOPIEQLGD - . . . . . . . . . -MHDEEIEWRIPAV 2404

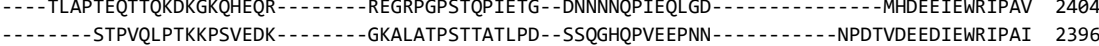
$*: *$

TTTARSLGFRSIRGTT -FKPETFKNIPRDITAIMRNDCATDAOYIOWESEVRADYDIATEGEWNTVFTAWLLYCANNGTTDKYNPLDVIP 2336 NKFERSSGFRKIGGRFVTTKQAIKSIPRDVRSLMRNDVATDNQFMAWETEVRDEYSVANDEAWQTLLMAWALFCAHNGTTNKFRHTDVMP 2345 NPNRGGVVIPTINGKKLWKRGILKHVPKQ-QYDATTTKATQTQLTNWVEAVKKDLRLKDDNAWALVLTAWCIWCADNGTSPEVDTNQELE 2506 SSNIVTSPVPVVNGKKLWKRGILKNMPKI -MFSTTSTMATOVQLTSWVEEVKKSLALNTDDAWTVVITNWCIWCANNGTSSE IDTSONME 2488 OKSSLSOLVPTIKGKKIWNHRVLKFIPDE -OFDVNAARAKDEEYSAWVDDIRSSLKIRSETDFOIVLTAWCLYCANSGTSSEMDVNOHFE 2467 QRLSLGRLTPKIDGRRIWNAKVLNGIPRE -QFRVSSALADDESYKNWEKEVKDALKIRSERDYQTVLTAWCLWCANNGTSSEVDTTQDLE 2559 PKTASHFNNPVVKGKRLWNSRIAKNIDPE -QFEQTSQKATTLQFERWVEKVKKNLGNPSEQHFQIYLTSWCLWCANNGTSSKVATNQMME 2491 PRRLSHFNNPRVKGKRIWNRRIINSIAKE -OFTQSSOLATTLOFERWAEDVRKSLGTPNEDDFOIYLTSWCLWCANNGTSSEVDVVNQTME 2501 AKSLRHISIPRVKGKAVWNOKILKKISKE -OYYETTOMATSENFEKWMEAIRKNLGTTTEADFOICLTSWCLWTANNGTSPELDPSOVME 2493 QKGFGHYKIPKVKGKRIWNPKILKKIAHE -QFTTTSQMVTTDKLEKWTEEVKRDLVVTNETDFQICLTSWCLWCANNGTSSELDASQFME 2485 GKGVERYQIPRVKGKNVWNPRIIKKIARE-QFTTTSQMVTQNQLEKWIEDVKRDLATTSNSDFYICLSSWCLWCANNGTSPELDTSQFME 2487

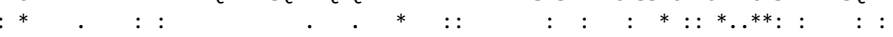

MPDGRGGTVDRQIGGFIRASSKV-GLRKLMRKFSRETSQMLLELGQMTKWGLKRGFODRGMIPYAFDFYVFDEMTPPWVREQLSSAKHSA 2425 MPTGOGTTTDVOIGGFVKASOOV-GLRKIMRKLSRETSOMLNELGEMTKWGMGHGIHDNWMIPYAFDFYLEDEYTPPPVHDRLAAAKHAA 2434 IHDGLGKVOAVKIDTFVDPAIENGGLRKIMRHFSGITOEILAKGGRMSAYGIKRGFTDNIMIPYAFDFMVANKRTPKIVREOLAQAKIAA 259 IRDGFGKVQEVPIEIFVNPAVENGGLRKIMRHFSGITYEILKVGKQMTAWGNKRGFTEKSMIPYAFDYYVVTNTTPKTVREQLAQSKAAA 2578 VHDGNGKVGLLPAKIMIDSAVKNGGLRRIMRRLSEPTSOMLAKGGRLTTWGIKRGITRREMIPYAFDFYVATSSTPKTIREOLAOAKIAA 2557 VFSGDGKVLKIPIRVFTEPAVEOGGLRKIMRRLSEPTTLMLKKGNVMTAWGTKRGFTOKSMIPYAFDFYVOTTTTPKTVREQLNOAKAAA 2649 IHAT -GQFASIPISIFVDPAIEFGGLRKIMRHLSDVTSKILEQGGKMTAWGKKRGFTQLAMIPYAFDFCVQSLKMPKTVREQLNQSKAAA 2580 IHSG-GKYSTIPIAIFVEPAVQNGGLRKIMRHLSDITSQILAKGGKMTAWGTKRGYTQLAMIPYAFDFCVQTNGMPKTVREQLNQGKAAA 2590 VHAN-GQIIEVPISIF IEPAATLGGLRKIMRRLSGVTSKILEEGGVMTAWGKKRGFTORTMIPYAFDAYMQTDSTPKIVREQLNQSKAAA 2582 VHAN-GOIMGIPIOIFVEPAIOHGGLRKVMRHFSGITSKMLSEGGKMTAWGRKRGFTQRSMIPYAFDFFVPTDTTPKTIREOLSOSKAAA 2574 $\begin{array}{ll}\text { VHAN-GQIMGIPIQIFVEPAIQHGGLRKVMRHFSGITSKMLSEGGKMTAWGRKRGFTQRSMIPYAFDFFVPTDTTPKTIREQLSQSKAAA } & 2574 \\ \text { IHAN-GQVTGVPIQIFVEPAILHGGLRKVMRRFSKMTSRMLAEGGRMTSWGIKRGFTDRALIPYAFDFFVQTETTPRTIREQLNQGKAAA } & 2576\end{array}$

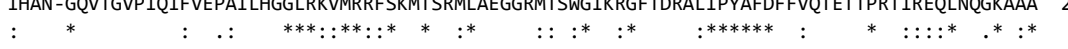

LGRGVRDTLLLDDKHHDASAQI-RSRNDQRESF-......--KAPEY 2462 LGAGEVDAMLMEKKHHDLQTIV -RPRTAQTERF - - - - - - - RAPEV 2471 IGHGIRRSLVTDGSVNGSKTSYERHTDQDQDEFEHGHDV-DRRPHLT 2642 IGSGTVRKMILDGNIQGSHASYERHVDTDNSEYEHGSSV-DQRPYLT 2624 IGSGVHRVMVTDGKLQRARTSYERHTDDDVTEHEHGDHG-DERAYLD 2603 IGKGVORVMLLDGKIOGSRTSYERHVDTDKDEYSHGDGGEDTHPHLY 2696 IGSGHORVMLMDGKIORSKTSYERHVDTDVDEFEHGGAI - EPRATLY 2626 IGSGYQRVMLLDGKVQRSKTSYERHVDTDVDEFEHGSMG-EPRATLY 2636 IGSGIQRALLLDGKLHRSKVSYERHTDEDRDEYEHSDNG-DQRPSLY 2628 IGRGVQRVMLLDGKVHGSRTSYERHTDNDODEYEHGGAE-DQRPALY 2620 IGRGTRRVMLLDGKTHGSRTSYERHTDGDQDEFEHGSLD -DQRPALY

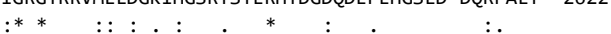


Fig. S2. Alignment of the "small" polyprotein sequences of SaPIV1 and BVMoV The PIPO segment is highlighted in cyan.

Striga-associated poty-like virus 1 Bellflower veinal mottle virus (NC_039002)

Striga-associated poty-like virus 1 Bellflower veinal mottle virus (NC_039002)

Striga-associated poty-like virus 1 Bellflower veinal mottle virus (NC 039002)

Striga-associated poty-like virus 1 Bellflower veinal mottle virus (NC_039002)

Striga-associated poty-like virus 1 Bellflower veinal mottle virus (NC 039002)

Striga-associated poty-like virus 1 Bellflower veinal mottle virus (NC_039002)
MDYLALTRIVANRQTIDMPRVLELAIKEVYGTYNRELNSAIDFK ---GEQLETTPATTDPLDVFIKNELKEINDAAGDCGKIACVRPRTL MDPLFLKRFNMDGGKLQICAPISDALKAAYNNHGVDIKSSYAVTAPCGTVISVENSTNEVLKDFVEAGMKFNDDVAGECPKGQCNEASKG

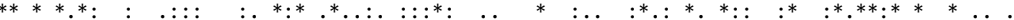

PEGFYATMS - -YAMGGLKGVIPGPVSKRRCFRDGYCYMNIFVAIAPHVYDEDALVYAKFLNDCPLVLGSWPTMNSLAKAMIWIGOKIPNL RSSWFLNCSPTLAVGGRSATF IMPMSPRRVFSSGYCYLNLAVAMSPYIFDEDAIKFAEFLHDLPIVLGKWPAMVKVARSFAWLLOHMPYL

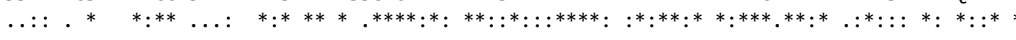

YNKAVPAVSISHTAEACHVVDQRGPVKGWHILDAPTFRDVILFSLKSDLSEYIIGG-DPVTAAYMHLSKCIRHANNTRQPWVTFNKMVLE CDRHIPHISINHNLNAAHVSDORGPMIGCHILNAYTLKDFVLTGMDTLNANTMLGGMDALTSAYOSLDKAIMQANKSFOPWLTFYRMICA

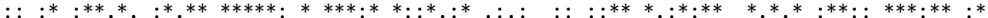

DSALAATLVLSPATLIKLESWFEDREEFRRLVATIESGVGDALTRIIVIKRAIEGVKIHFLDNDIETATAALHORVLEYIRNADDGGA - DSMLAATLIMSPATLQKLESWFEDDEGFRRVVATLETTVSDALLRMVIIKRAIHGVKMHFRTDNVERSTNELHRAIIAYIDSQDDQSAKD

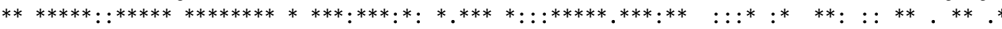

LNAAATRFSNLVTEKKRAVLLFRKTDSLTFRFSLATRARFWCYIYRRKLLYWSYSHVAKHFTISRKTRS - . . LGDAARRFETMALEKKDAIRVLRKFNSPLFGLSLASRARFQLYIMWRKFVYFAATKARKLYTCNSAPRAEGTAARIHTRGOIHMGNHLLV

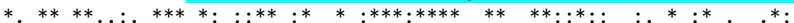

421 RASSKPHVAGVVFN 464 
Fig. S3. Alignment of the polyprotein sequences of SaPIV2 and CeLV

Putative cleavage sites are marked by vertical bars $(\mid)$ and highlighted in yellow. Striga-associated poty-like virus 2
Celery latent virus (AZJ53460.1)

Striga-associated poty-like virus 2 Celery latent virus (AZJ53460.1)

Striga-associated poty-like virus 2 Celery latent virus (AZJ53460.1)

Striga-associated poty-like virus 2 Celery latent virus (AZJ53460.1)

Striga-associated poty-like virus 2 Celery latent virus (AZJ53460.1)

Striga-associated poty-like virus Celery latent virus (AZJ53460.1)

Striga-associated poty-like virus 2 Celery latent virus (AZJ53460.1)

Striga-associated poty-like virus 2 Celery latent virus (AZJ53460.1)

Striga-associated poty-like virus 2 Celery latent virus (AZJ53460.1)

Striga-associated poty-like virus 2 Celery latent virus (AZJ53460.1)

Striga-associated poty-like virus 2 Celery latent virus (AZJ53460.1)

Striga-associated poty-like virus Celery latent virus (AZJ53460.1)

Striga-associated poty-like virus 2 Celery latent virus (AZJ53460.1)

Striga-associated poty-like virus 2 Celery latent virus (AZJ53460.1)

Striga-associated poty-like virus 2 Celery latent virus (AZJ53460.1)

Striga-associated poty-like virus 2 Celery latent virus (AZJ53460.1)

Striga-associated poty-like virus 2 Celery latent virus (AZJ53460.1)

Striga-associated poty-like virus 2 Celery latent virus (AZJ53460.1)

Striga-associated poty-like virus 2 Celery latent virus (AZJ53460.1)

Striga-associated poty-like virus 2 Celery latent virus (AZJ53460.1)

Striga-associated poty-like virus 2 Celery latent virus (AZJ53460.1)

Striga-associated poty-like virus 2 Celery latent virus (AZJ53460.1)
. MSKRIYTIIVVLCFQVCFQNLRTQPTQSSHTFSTNPAIPGTDALQFEENANLTYSTIKYNILKFNLNYKQSIMSVVSFGSITSMDFDAAC $*:::^{*}:::^{*} \quad * * * * .:{ }^{*}$

- IDGPTTEVPQLPTAAPVRNQAERLVRAL LAAMIETPGGSIPPTPQSPPTSPVAVKQRKILNFPIAKIRTTPDASFEMCVKFPESFIDSFCAQAQKELKYWHAAITQLKFFGGETPKTL

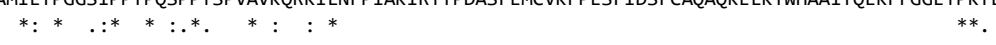
EALEVNQGQAHTHQVILNLVKILDSAPKAIQGKKELENFFQLSPHGNNSKEPIDVSRKVYMEPCKISPRKRQVCSCDNDDDAHYHCYYCDI 270 $*: * \quad \cdot * * *$ :

$$
:^{* * *} \text { : }
$$

- - VLSNFQWGSLSARFYNPKGVGHDI -

LEKKMVLVKSTHR-........ VCSSKNLLQEHERDFCEDAQSVQAFGYKLESPNVFDPPHVTQQRSVAPSLGKTLESPVKSPEQSKPNLEKSFPLVESSTNSGMIFFGSIA $:$ : $^{*}: \ldots::^{*} *$ * : $\quad * * * .: *^{* *}: *$.

TMPSHIEKY TMVPSHIEKYVRNCETENPIDAAASNLAMQEAKSSGAPCIVVHHKALPGGKKDFLFPHNSPQVVRTETEEPIAGTIDRPTIKRALFTRIK $:^{*}:: \ldots$ : $^{* *}:$

TTEKQILVRPGANICAKTKRPLRPGEVKQLIKATGDPQHPLFCLPITKLIETTHPIYRIEIDAKEEFYVLRGDVRLLSRRQRQKLHQKRW KKAQEICVNPGGTIQRKTKRWLRPAEVAQIVRATSDPQHPLFKVDVTQIIEVVHPVYRTERTEVVQQCITRGTYKLMSKAQQRKARAMRS

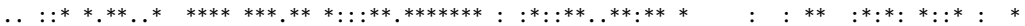

NKELVIDESDTSSWNSREHWVEKLVPKKAYTKYIKCGKLPEELEP- - -WTNARNSDDFELPSKNKLKKMS - TAQKLACVDKNNFEHDLKGH AGMLVITDNPTTHWVSEPQKMLVVKEKLSTTKHVKLRNVEVNAESEMFWGTKTK -----EGPSKTALKRCKRNIDRLALLDPQMGESANGE

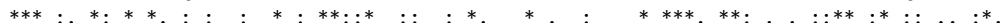

CWRNIFTDRISFGDMKSQPKGWHEHRFGRVKGSFIPLVKFCELLQEEVARFPSLAEMLVPRPFCYREGGRLVYHVGYSKFSRGFCSLQSL CWMNTFKHHLKVGSIDILPNKVRLPNLRSAFSRWIPLVDYVEILKFHCKSQPKLKRVVIPTPVTYLEGSRYHIHVGYSK -NCSWITVEQL

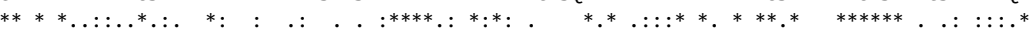

LHPPIKSGNPKVPKSVLLEAVVGAEPTEDVETFDTIDWEFDLGVPIVDIDLASKVAGTLEVAEQIADYQTGTTYGEPNDVTACELGHCYH IRQLQTLLTSSKYGEHFKRAIVGGEPED - - - - - . - - - KFTPVVPIVDVE - TERAKSSLAKWTTAQQRYMGSIRTRINSQAEKHKIDSEK

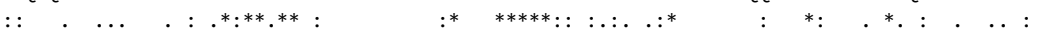

KFWWDPSLPVWKNDVNRGICIAMTRSFRENKMYLRDFLVQLEDQESMGFIPQVKVVATPF IYCLKGRLYMHVGDHPEGANCGRNDALRYI KIW- - - - IPMRHDTMD - - - -MLTPPYLFENG - - LRNNEVQQVGQVLGDSVDRAGNSSGQSSQCQQQNVAL - - - - - - - ASEGNNDNV - - I

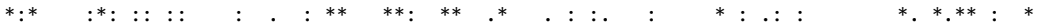

HEFSRRLPYHLWKEVIVGASPIKKKKWFQVTNSGEELSGEELVTVNRKELLKLLRHQQKLSSVASGLVGENCVRPSGSESSSSELFEMLNS

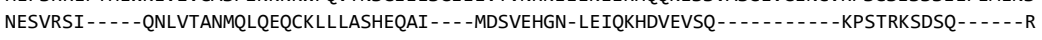

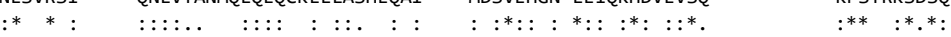

ELSRSAMNCGNASSLLKRTELNGNKQHGKSLKFWESKWMPILGPLLGVSSLEILHOMOMREGGSWLDLGISNKLFOMTSTVAIRSMQTYF NLQKFSLKKIVASEEMSRTLGRG - - - . - - - - - WRKSVTSIGVPIVSASIAEALNQVVQRGNTSWLDVGISGTLLKQCTLFATRTFQAYC

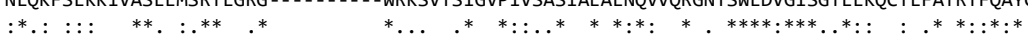

TAKMIKGIWNLSKSEVHMHVMKQVHSLHESAGAETLRVKAWYANLPASVKILFIGAIFMGSVHFVRKLFRVKVVNTDGNRADGNFSEVVR SYKLARNVLTLTVGELYDNVKSYINSIMGSTDPEVTGFLSQVRSAPSMVKMAILLTMFAISVKLMRKFFKVKNNGTSFTVSGENVSASQL

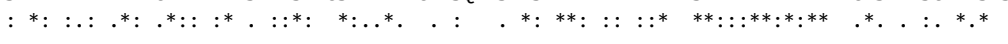

VSVSQRQALPHTQPSKQVKLFMTAAGMIATVSMFCDVRTARYIKEWMDLWWYAVTSATQMGSFTDLIMSPREYLKSIMDPQLGEQHAFNQ 924 RISAQAQARSTDNMTPTVKKLCSILGMIGLVCCCYDRTTWAYQKDWMDAWITSITYAGASDSIWESISHPFETLHNIAVSGGDRSPETTA 1187 :**. : : : **: : : **. *. * * **:**** : :** .*: : * ***:.* . ... RFLTLIRDAEQQQNGIENNSELTKTYMKNREALGMENPMSEVQGFLLHEILDQVQEAPFTYMGALKGLNEILVSHGTMYQIAKDLAEGFL 1014 RLERILAGA--- - GLNAQAQALDEF-- - - - - - -GASSSVMGQTLQNILDEVESTNVSIVSEMKALPHYHRNATTFNQAARDLVTEPD 1262

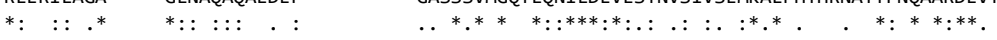

KEKFNLLNAPTGSGKSTIFPAYVSARTKKRILILVPLVAATMGIYSRLNEKLPNQVGYHADKTSANVHAKIIVSTYGHIAHQLMQGMDPY 1104 ATYQMLLTAATGTGKSTLFPVHLRSOSOKRVLLLIPLVAATHGVYORLKSORVNDIGYHADSISENPNAKLIISTYGHMCVKLLGGONPF 1352

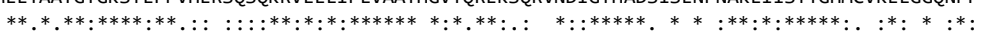

ENYGIILADECHVSTLETAVVITDLLARKRNMQQSVMFMTATPFKHLTLESVATEQDVQQVRTSKFQSVKTFINYCREGGEQRVLQTAEN 1194 DQFDYILADECHVVTLETVTVISHLLQQREMATWKTVFMTATPFNNITLNSVETEQPVIMQQTEHFHNPKSFVDFLKAGGTERVQTYAKG 1442

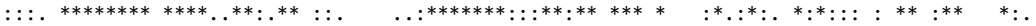

GCIIFCATHKEVVELASFLNSPSHPAIAYHSGLRSPLGEFIEKNKDRLGKFPYFVCATNALESGVTIPARTCIDFSTKIVSQVEGDRNTV 1284 GCIVFCSTQKETEESAKALKASGVIALFYHASNRLEWDSFAKKNERSMGQLNFYLFATNALESGVTIPMKSCVDFVTKMHPVVGGDRKTI 1532

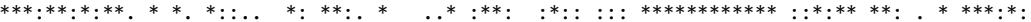

SMARQTITMPEQIQRRGRIARTQPGIYLYTHAGEQNQVRLDPDSSVKYLLNCWVNRTVCCKEICDLPDESTVRITRAMVPMVWCHDTPPL 1374 TMAPTSISIQEQLQRRGRVGRTCPGGYLYTSVGTPLMYKLDPDSSIKYLLYCWKSGIKCYKEALNIPDECTITFTKEKIGAIWTHDTPPV 1622 $::^{*}::^{*}::^{* * * * *}: .^{* *} * * * * * .^{*} \quad: * * * * * * * * * * * * . \quad * * * \quad::^{* * *} .^{*}::^{*}: \quad: \quad: * * * * *$ :

VQCSLMDHLGCIFQNAIEFCGAFQSVPGQMPATTTMLDSTQVAKFHVMTVTLTNSDEVQDLKVPQPHHWFNEPRVVALWNNLLKSSSFEL 1464 VTAALVDNFGAVYRNANFFLASHRRNYVEIPHTTDMILPSTLSTWENFELDGNEVSDGTRMRVPQNHFFFRNERVQESWLKLQAAILTEL 1712

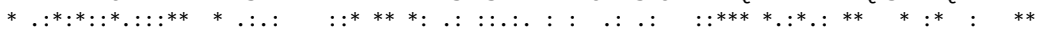

TPGECSERKNNMLARLESQVAYNSTSTDLDLASLLAKFYENIKVFRQQISAMQSFTANTLEKTAFLDSFSLLSFANKNIRLRSEKRIKEI 1554 TEAEATKKRDIVIENLMARRVSGHPASKLEIARMIMAKQQVVQQARDTKRVRETLSESISDYSGIFSNFSGIFSVQERLKKASIKANEEL 1802

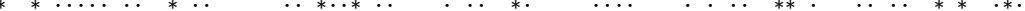

EQDIADTEACILFLEARLTGQCDANLAIEKTEQDKIKEYLACLMDMGYAKGSFQSCFFIRETTWRRFRDFVDLLPDGTYRQKSF TKRILE 1644 DMVIQENESHILFLQDMIKETPEIIPDMALEEQIQHMEYAKAILENGWISGNPQAKLLIMRTTHKNFHDLVTKTKDGTYRMKSYVQRMFD 1892 $: *^{*}: .^{* * *}: \quad: \quad: \quad: \quad * *: *^{*} \quad .::^{*}: .^{*} .^{*}::^{*} .^{* *}: .^{*}::^{*}{ }^{* * * * * * *}::^{*}:::$ 
Striga-associated poty-like virus 2 Celery latent virus (AZJ53460.1)

Striga-associated poty-like virus 2 Celery latent virus (AZJ53460.1)

Striga-associated poty-like virus 2 Celery latent virus (AZJ53460.1)

Striga-associated poty-like virus 2 Celery latent virus (AZJ53460.1)

Striga-associated poty-like virus 2 Celery latent virus (AZJ53460.1)

Striga-associated poty-like virus 2 Celery latent virus (AZJ53460.1)

Striga-associated poty-like virus 2 Celery latent virus (AZJ53460.1)

Striga-associated poty-like virus 2 Celery latent virus (AZJ53460.1)

Striga-associated poty-like virus 2 Celery latent virus (AZJ53460.1)

Striga-associated poty-like virus 2 Celery latent virus (AZJ53460.1)

Striga-associated poty-like virus 2 Celery latent virus (AZJ53460.1)

Striga-associated poty-like virus 2 Celery latent virus (AZJ53460.1)

Striga-associated poty-like virus 2 Celery latent virus (AZJ53460.1)

Striga-associated poty-like virus 2 Celery latent virus (AZJ53460.1)

Striga-associated poty-like virus 2 Celery latent virus (AZJ53460.1)

Striga-associated poty-like virus 2 Celery latent virus (AZJ53460.1)

Striga-associated poty-like virus 2 Celery latent virus (AZJ53460.1)

Striga-associated poty-like virus 2 Celery latent virus (AZJ53460.1)

Striga-associated poty-like virus 2 Celery latent virus (AZJ53460.1)

Striga-associated poty-like virus 2 Celery latent virus (AZJ53460.1)
TARSHPWIGLSVCSAGVAICCYALFSTLKKSEDKGMKSIGNLETKSNVFHAHEVVYLPESMPYAGTLVKGIAISGASFLITRKISDLITD 1734 FVKKHPLLIFMSIMMGTSLAA -GYFMMSKDSEDD - - - - - DAIVQDKVFKRNDKAMLEWCLRGKACKCDATHFEAQYVLDSRHYRTILED 1975

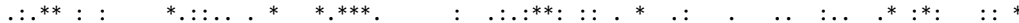

WVKFPLRGFHNIQIVNYGTVSKYARALAFLSVCALLANPTMVYNSAAHSMAGNSEYNESVAKSLMHNILRDWNRVPLID ---LLVKGIDG 2062

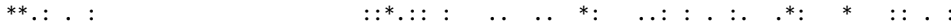

ALDEYKSRFLQKAITQGYVP - - - - - - EGKGKLRAHRTKALKKKTSEDQEPRGRMKAYYDPYSEGKTRRGLKKVFRQFYNVDDADVKEI 1877 SDDRYDQYIHELYTSGGLIAFESDTGKFEGKMSISQYRKDAAKGQTKRSAASRSREEDHYDPRSSGRLKSGIRRAYRQFYNIEDSDVQEI 2152

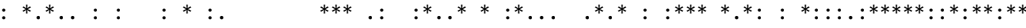

IHGEKHEPVLVISSLDALNAEVDRVKYSDPHLYALYQDVKEKLENAEDDDPEAYLQRIKETSEKIKGNARWVDFAE -DEMTDMIYALQN 1966 ILTNKKGAPILKIGSLDELNQHVDLLKFSDPELYELYLHARDKLDLDEPESSSGF - . . . . . . - TGKWGDYAEDDEFMKMISALDS 222

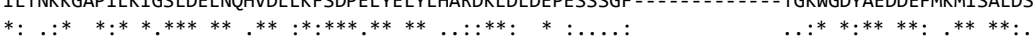

LVKKASEEAFIPVTVKTYDGRTIQATVANYRGK - . - . - - - -WQETSWPRIDNSELRQKLDDALRMLPEGFVSKIKDDCTDEQAHEIDE 2046 LTKOASEEAFIPVOVKLRDGRTVOANVARYWOKDYPTGKSVKOWAOTTWAPPOFTALRERVGKALELIPESRPIHLHGKVPNGTLIEFOD 2319

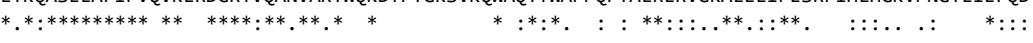

LVKCVLHENARKQNREAVMPGTQCQTDVCDWTPRVGIIHRKDEEGNFTQVFLQCIALNNVCIYPYHGWLSDGEELQFHFPTTTFVGKMKR 2136 AMKDLHEKTAVKAVAEAKIGDTOFEADPSDVTSRVGVVMVKTSANAEWESWNOCVALNNIVIFPHHYTLKDGNNLRFKFSSSDFESTCHI 2409

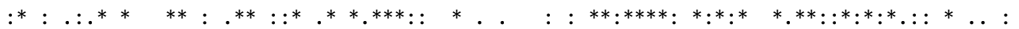

SEEFGNNDIAYTPLPKRIKGVSGGVILSKPSEKENVFHFSRIVSQKVKTEVQYQGFSITAHIDGNC - - - - -WAHTVPTQVGSCGGPMLNM 2221 VDGYNGLDMAWAPINVKIRGLKKKVCLGTPRNGSYLWHFSMINQGKDLPEARLMGYSSVTKVQEESHPSFDWTHTVSTQVGNCGGPFVDK 2499

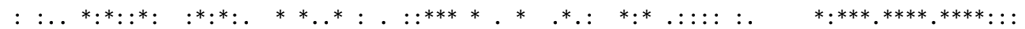

NIa-Pro|NIb

RGHLIGYHVGTAGDFSYNDFLGFSEELIKSIRKIDVSRTARRQGMMEWRETEFYKTSNYMPPMLNRQ|DPIPEEWQAPAHKDIKRCTDAD 2310 HGVIVGYHTGAFQLGQFNTFLGLSAPLIAHLTKLDVKPSAOPOSKMIWREVDFYRSPNYLPPTINNO|EPIPEEWRYPEGKSVYPCVDPG 2588

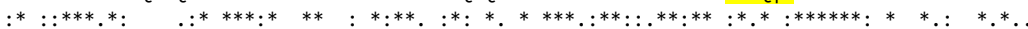

WMARELLKGPSFELLGKMTRMVDYNTKISKNQDFAIWFNLEETKRHLDEINERRALRNLEPLHISHTISAQNREAAILDTSKYNRITKYT 2400 WMGSRLVKGSGFRLIGKMQRHVEYSTKISLNEHFDMWMSQEKTQNELTRLNKNRVEKGLEKAFISHTIAAQNKEAAIKDTSKYARTTLGT 2678

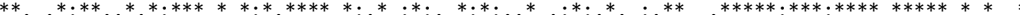

WSDDLLHKATQMVINLLEPHIQKCARQPLELVYQDMEWSTACGARYDGLKADFRTRVVGETNMMAYGEYAWARFDVPAKEYVPTIWTNSL 2490 YSEPLLKRATALTIQMLEEHIKLCKRQPLDLVYGDMEWNTACGAQYNGLKSAFRDQVVGIENMDAYGQYCWERFNVPTDQYKPCIWTNSL 2768

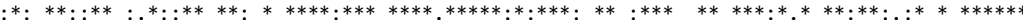

KDELRPIEKVEANKTRTFTAAPIDFVVGAKQAVDQFNHQFMAKHLTLPHTVGINQWSGGWHRLYQKLEGKNFLYSSGDGSRFDSSPTSEM 2580 KDELRPIEKVKENKTRTFTAAPIEFVIGAKQAVDAFNHQFMDAHLKLPHTVGINQWSGGWHKLYKKLYGKNFVYSSGDGSRFDSSPCFYM 2858 $* * * * * * * * * *$ : $* * * * * * * * * * *: * *: * * * * * * * * * * * * * \quad * * . * * * * * * * * * * * * * * *: * *: * * * * * *: * * * * * * * * * * * * *$

FDAIYTIRCHFADKSMWOVLNNIYTEICFTPIVLHDGNIVKKDHGNNSGOCSTVIDNSLIMLILCCAAYLEHTPPSWHSVKOMNEHWHFC 2670 FDALYTIRTYFADPEIHQVLENIYLEVCHTPIVLHDGNVVMKNHGNNSGQCSTVVDNSLIMMILCCASYLEHTPATMHSLDAIKSHWHFC 2948 $* * *: * * * *: * * *$.: $* * *: * * * *:^{*} . * * * * * * * * *: * *: * * * * * * * * * * *: * * * * * *: * * * * * * * * * * * * .:{ }^{* *}: . \quad:: .^{* * * * *}$

VNGDDYIGGMSPQLAKLLTKERMALTFDAFOFKYEWSDYSKSLFDQEYMSLKFIKINSDDTFPTSKALIAPWREGSROLSTLSHTTSFEP 2760 VNGDDYIGGMSPLLASHLTKEKMAKTFSDFQFIYEWSDYSPSLFEQDYMSLKFINIVERKGQTTGQQLIAPWREASRQLSTLAHTSSGAP 3038 $* * * * * * * * * * * * * *$. $* * * *: * * * * . * * * * * * * * * * * * *: *: * * * * * * *: * .$. . $^{*}$. : $^{* * * * * * *} . * * * * * * *: * *:^{*} *$

WIKLQVALTERVKAWVDRDLFEFITSYAKWYLNHVGESCQRKEWQEVQALWWDEQHIFNHYFSRESARSQGSIELFRSMPEGEDIIWGPR 2850 EIKLOVALTERVKAWVDKDLFDFITEYCRWLVEYFDRFTNTOAWNEAKKLWWDEOOIFNHYFSFESICNAPYSOIVNETPD -EFFANGVR 3127 $* * * * * * * * * * * * * * *: * * *: * * * .^{*} .:^{*}::: \ldots \quad::^{*}: * .: * * * * *: * * * * * * * * * \quad:: \ldots$ : $^{*}: *^{*} *$

ESFNFEV-EDGSEVRTS - - - LGNADSSL- ESRPLRILRDGIKFGVAVTAANYLGPSDHDVPMIANTMLNVAKIGLANSTAERIDRMLFGKENPEHSRADSLVVVKTEQTDATICLRTHC 3217 ** $: .: . * *: . . \quad * *: * .: \quad * * *^{*} \quad: .:: \quad:: *::: *$ $\mathrm{NIb} \mid \mathrm{CP}$

PCPSEH - - AFORRDFNOKNLLRFCTTEWIEKLESYDFYELPESLYEOOEILFHVWFHILKG - - - - OTVOOIO|NDLSLTRSRKMCSVAH 2979 KCOAQHFDGKYECWVSSPSVAIKMFATLKPRILSTTKFVGVK - - FLPKILRAHVWALYLSGFSWEETMQIVQ|SHYPGEKOORK - - -AD 3300

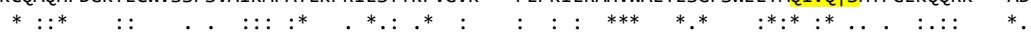

WFSRQIIGVCICHYQNDNGKMNYKGVITILGKSSKLNTNNRQAMTTVVATPQHY---FRLTNPQGFGNDAQAANAAWNALSEADKEAWRQ 3066 WFLQQLLKELVLIFKVKGSKF - - - - - IELGEHAQVQGKTQLDSTQVDMDPNFNAAAYAATLRGGPHWGTHNSQGLFDAIKVLNPNA - -A 3382

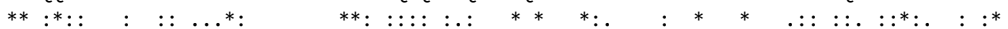

RFEALPVHNGQRRISDQEIVPPRQRREERREEQHEQQRPPPQGGARIAHGENAKRQQSLMQKYGNILTTAEPEGFKQDVMSSKAVGLVEN 3156 NVDIGNARTAVQREMORLIAADAPROOPPPOVGGGHOOPPPAGGQTOGQPGGYTPSOAFTNKFGNIMAEPDAPLVLDSOATMREVAOIEA 3472

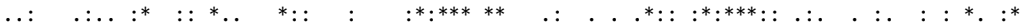

RWARRCGLPNGASLVNHPEFWRFIFTYVCNNGTSTSGNLEQEFMVNEEIIKISMLVDDANQHGGWRRFWRSKADDLYNFLAILKENGENM 3246 AWAR---LLEVQSLEGLGSFWNYMFSYVGNNGTSSGGDPRDYIPAGNGRVTLAQLKSKA-QGEQWRRYWRSHASDMRDFLRLLQASDRPL 3558

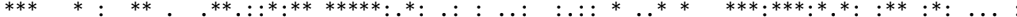

PIDWAKKNGFPPEHSHLGFDVVDYCKDLSPQEKQVLAAIKARAVPRNRGTLVGTSLKPNTGGDEETYGNVDRDIVR-DMGGGFR 3329 PIRWARNNGIKDANYEIAFDFADALPDLSAAQMSIILAAKNLAVRRGQGQMLNAGTKVGGRSRTETYDQAVRDAADVQFPGA- - 3640

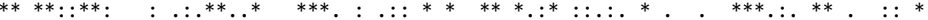


Fig. S4. Alignment of the "small" polyprotein sequences of SaPIV2 and CeLV The PIPO segment is highlighted in cyan.

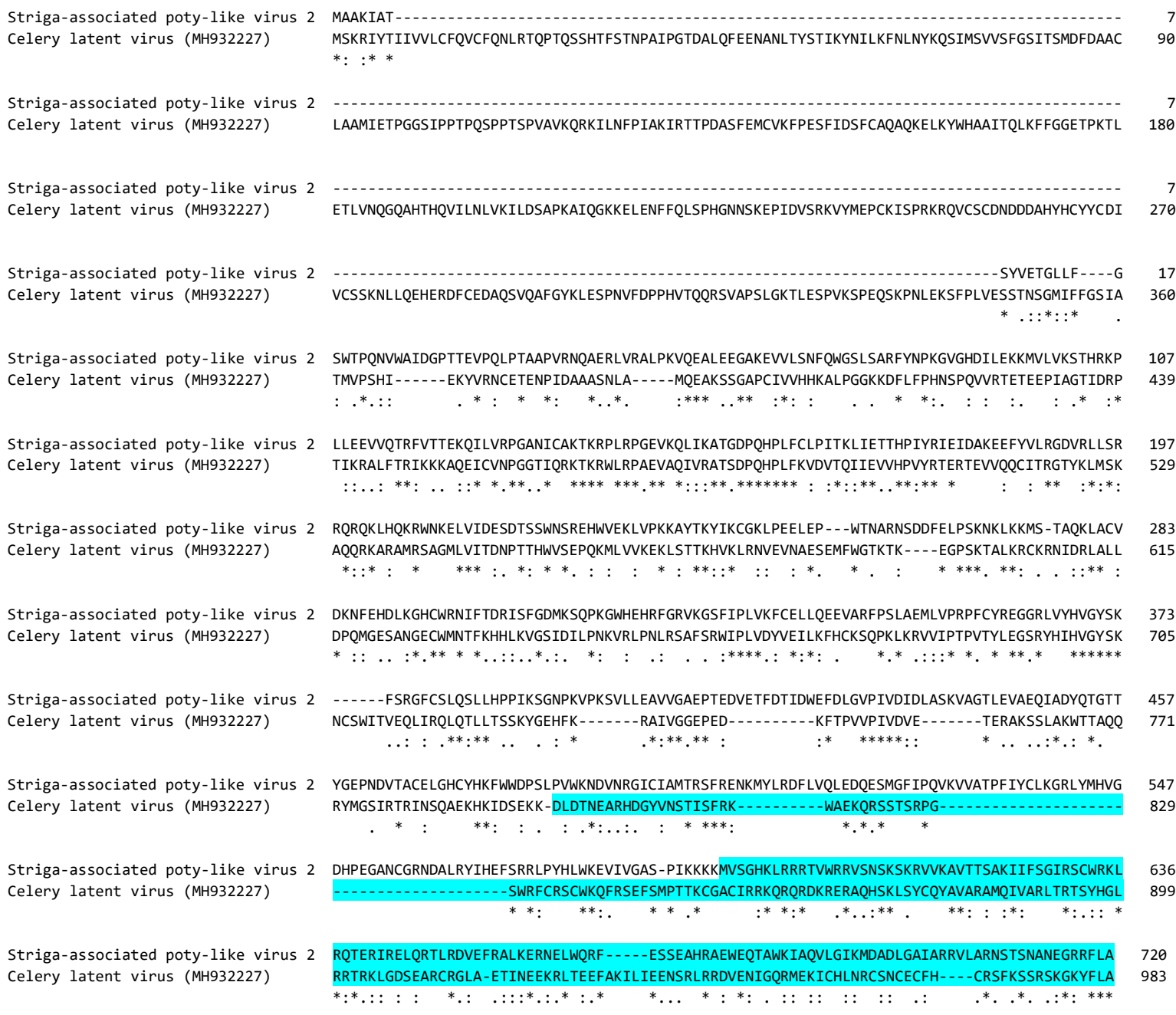

